\title{
An Overview of Own Tracking Wireless Sensors with GSM-GPS Features
}

\author{
Hamed Yassin-Kassab, Marius-Corneliu Rosu* \\ Applied Electronics and Information Engineering, Politehnica University of Bucharest, Romania \\ Received 27 September 2019; received in revised form 28 December 2019; accepted 20 January 2020 \\ DOI: https://doi.org/10.46604/aiti.2021.4793
}

\begin{abstract}
Wireless Sensors (WS) mobility and pause time have a major impact directly influencing the energy consumption. Lifetime of a WS Network (WSN) depends directly on the energy consumption, thus, the hardware and software components must be optimized for energy management. This study aims to combine a compact hardware architecture with a smart energy management efficiency in order to increase ratio Lifetime/Energy Consumption, to improve the operating time on a portable tracking system with GPS/GSM/GPRS features and own power. In this paper we present the evolution of own WS tracking architecture with GPS/GSM/GPRS features, basic criterion being the lifetime combined with low power consumption. Concern was focused on hardware and software areas: Large number of physical components led to reconsideration of hardware architecture, while for software, we focused on algorithms able to reduce the number of bits in transmitted data packets, which help to reduce energy consumption. The results and conclusions show that the goal was achieved.
\end{abstract}

Keywords: WS, GPS/GSM/GPRS features, portable devices, operating lifetime/energy consumption

\section{Introduction}

A typical embedded system involves the following main features: Sense, process and store, transmit, and power management as shown in Fig. 1, while the first order radio energy consumption model is shown in Fig. 2 [1-2]. Since computers and software have made their presence in every component and as part of communication and automation, the structure described above has changed, and concern has materialized in both hardware and software direction. As electronic components manufacturing technology has evolved, specialized companies appeared in achieving their specific features dedicated to the purpose of use; thus, at least hardware designers can choose components with low noise and minimal power consumption. In the software part, the remote data transmission algorithm has focused on minimizing the number of usable bits for data packets, the next packet following will be transmitted or not, depending on the decision taken locally in the WS, so that the active transmission time would be shorter, which reduces the energy effort in the sensor.

Ideally, we want a network to have a long life and to operate unattended, but there are factors that limit the capacity of the power source. The issue of energy consumption has been divided into two different directions: First, a large number of efficient energy communication protocols have emerged, including MAC protocols, routing and self-organizing, which take into account the particularities of Wireless Sensor Networks (WSN). Secondly, local Dynamic Power Management (DPM) strategies are developed to detect and minimize the impact of inefficient activities on an individual node.

\subsection{Energy model description}

As already mentioned in the introduction, the model used for radio energy dissipation is shown in Fig. 2 and, accor- ding with literature, it is a first order radio model [3-4]; the definitions used parameters are shown in Table 1 [3].

* Corresponding author. E-mail address: marius-corneliu.rosu@sdettib.pub.ro 


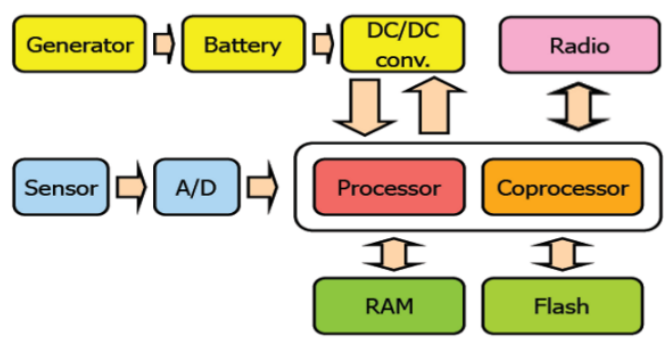

Fig. 1 Typical embedded system

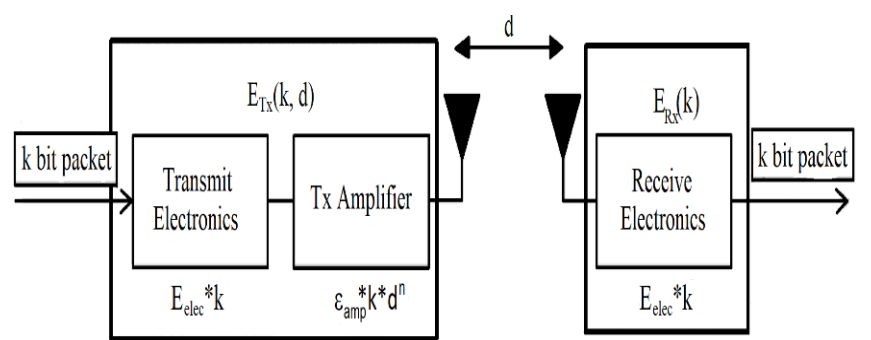

Fig. 2 Energy dissipation model in Radio transmission

Table 1 Graph representations

\begin{tabular}{|c|c|c|}
\hline Parameter & Definition & Unit \\
\hline$E_{\text {elec }}$ & Energy dissipated during transmission / reception & $50 \mathrm{~nJ} / \mathrm{bit}$ \\
\hline$\varepsilon_{f s}$ & Free Transmitter Amplifier Model & $10 \mathrm{pJ} / \mathrm{bit} / \mathrm{m}^{2}$ \\
\hline$\varepsilon_{m p}$ & Multi-path model of the transmitter & $0.0013 \mathrm{pJ} / \mathrm{bit} / \mathrm{m}^{4}$ \\
\hline$k$ & Data length & $2,000 \mathrm{bits}$ \\
\hline$d_{0}$ & Threshold for distance & $\sqrt{\varepsilon_{f s} / \varepsilon_{m p}} \mathrm{~m}$ \\
\hline
\end{tabular}

When $k$-bits message is transmitted over a distance a $d$, it will consume an amount of $E_{T x}$ energy according with Eq. (1) [5]:

$$
E_{T x}(k, d)= \begin{cases}k \cdot E_{\text {elec }}+k \cdot \varepsilon_{f s} \cdot d^{2}, & \text { if } d<d_{0} \\ k \cdot E_{\text {elec }}+k \cdot \varepsilon_{s s} \cdot d^{4}, & \text { if } d \geq d_{0}\end{cases}
$$

And the $\mathrm{E}_{\mathrm{Rx}}$ energy needed to receive the transmitted message is given by relation Eq. (2) [3]

$$
\operatorname{ERx}(k)=k \cdot E_{\text {elec }}
$$

To forward this message, the amount of $E_{F x}$ energy needed is given by expression Eq. (3) [3], where $d_{0}$ it is defined in Table 1 and expresses the threshold for changing the amplification patterns.

$$
E_{F x}(k, d)=E_{T x}(k, d)+E_{R x}(k)= \begin{cases}2 k \cdot E_{\text {elec }}+k \cdot \varepsilon_{f s} \cdot d^{2}, & \text { if } d<d_{0} \\ 2 k \cdot E_{\text {elec }}+k \cdot \varepsilon_{f s} \cdot d^{4}, & \text { if } d \geq d_{0}\end{cases}
$$

\section{Background and Related Work}

\subsection{Background}

In this section we will briefly review the theories and technologies relevant to the subject of this paper. As autonomous devices, available energy and other resources are limited in size and cost, being directly dependent on the range of available energy (e.g. battery energy density or external energy capture devices); computational resources, storage and communication, all of these vary from one system to another. The design challenges for such WS devices and are illustrated in Table 2.

Table 2 Design Challenge Issues

\begin{tabular}{|c|c|}
\hline Design issues & Determined factors \\
\hline Dynamics of the network & Mobility of WS, target and Sink for WS \\
\hline Node location & Deterministic or ad-hoc \\
\hline Inter-node communication & Direct or multi-hop communication \\
\hline Data transfer models & Continue, event-triggered, on demand, hybrid \\
\hline Data aggregation & Internal network (partial - total) or network external \\
\hline
\end{tabular}

Tracking systems are a way to monitor, detect, and then notify users of certain activities. Such systems use different types of technologies that are covered by the Internet of Things (IoT). To determine the most accurate location of an object, the Global Positioning System (GPS) represents the main technology for such purpose. 
A GPS tracking system involves three layers [6]:

(1) Space layer, composed of at least 24 geostationary satellites orbiting twice a day;

(2) Control layer, consisting of 5 stations across the globe, monitors and manages satellites by updating orbital data and clock correction.

(3) User layer, consisting of all kinds of GPS receivers; they have the ability to receive data from satellites.

Once the receiver sets its position with the GPS satellites, the information is usually delivered in one of the following formats: 1. Latitude and Longitude and 2. Universal Transverse Mercator (UTM); GPS receiver provides location and time information about any object anywhere, anytime, as long as the communication path is not obstructed by any obstacle.

When WS is in contact with at least three satellites, two-dimensional position (latitude and longitude) is determined by triangulation method [7]; we must remember that the satellite emits a signal with a certain frequency.

If four or more satellites are detected by our WS, then it is able to calculate the position in three dimensions: latitude, longitude and altitude; after that it is possible to calculate vehicle's average speed and moving direction. GPS technology has the following drawbacks [6-7]:

(1) They consume large amounts of energy;

(2) It is not efficient for indoor locations;

(3) It needs a free line of sight for at least three satellites;

(4) Detects position approximately;

(5) Yield is weaker in crowded areas.

However, simultaneously it is also necessary the access by mobile communication network GSM/GPRS who made possible online tracking of the system; we make it clear that GPS tracking uses the global satellite network, while GSM/GPRS is the mobile communications terrestrial network. A clarification in this respect can be found by the reader in Table 3 [8].

Similar systems have been designed and built by researchers, tailored to the specific requirements and purpose pursued (e.g. in the health field). There are five major classes, generally accepted techniques for energy efficiency in WS, summarized in Tables 4-5 and shows how each technique addresses energy-consuming processes.

Use of energy must be tightly controlled; energy efficiency means adapting the power cycle to the node's operating mode.

Table 3 Comparation GPS-GSM/GPRS

\begin{tabular}{|c|c|c|}
\hline $\begin{array}{l}\text { Terms of } \\
\text { comparison }\end{array}$ & GPS & GPRS \\
\hline Semantics & Global Positioning System & General Packet Radio Service \\
\hline Scope & It provides positioning services & $\begin{array}{l}\text { Offers voice\&data services for } \\
\text { mobile telephony }\end{array}$ \\
\hline Applications & $\begin{array}{l}\text { Navigation, Surveillance, } \\
\text { Mapping, GIS, and others }\end{array}$ & $\begin{array}{l}\text { Access on E-mail, Multimedia } \\
\text { messages, Video calls, etc. }\end{array}$ \\
\hline Operating & $\begin{array}{l}\text { Communicates with a collection } \\
\text { of satellites orbiting the earth. }\end{array}$ & $\begin{array}{l}\text { Communicates with a terrestrial } \\
\text { tower. }\end{array}$ \\
\hline $\begin{array}{l}\text { Minimum number } \\
\text { of stations }\end{array}$ & 3 & 1 \\
\hline Use & $\begin{array}{l}\text { GPS is used anywhere: sky, } \\
\text { earth, water, etc. }\end{array}$ & $\begin{array}{l}\text { GPRS - limited range and } \\
\text { available only on land. }\end{array}$ \\
\hline Costs & Expensive & Economic \\
\hline
\end{tabular}


Table 4 Design challenge issues

\begin{tabular}{|c|c|c|}
\hline Techniques & $\begin{array}{c}\text { Description } \\
\text { Data Reduction }\end{array}$ & $\begin{array}{r}\text { Reducing the amount of produced, processed and transmitted data. Examples: Data compression } \\
\text { and aggregation. }\end{array}$ \\
\hline $\begin{array}{c}\text { Reducing the } \\
\text { Protocols Size (RPS) }\end{array}$ & $\begin{array}{c}\text { Goal: Increase protocol efficiency by reducing overall costs. Transmission periods, adapted to } \\
\text { network stability or distance to the transmission source. Examples: Stratification approach or } \\
\text { Avalanche Optimization of transmitted data. }\end{array}$ \\
\hline Efficiency routing & $\begin{array}{c}\text { Routing protocols must be developed so that the network life will grow by reducing energy } \\
\text { transmission and avoid nodes with low residual energy. Examples: Opportunistic protocols taking } \\
\text { advantage of node mobility; protocols using geographic coordinates of nodes; protocols that } \\
\text { hierarchize nodes to simplify routing; protocols that send data only to nodes interested in avoiding } \\
\text { unnecessary transmissions. }\end{array}$ \\
\hline Cycle of service & $\begin{array}{c}\text { Express the fraction of times when the nodes are active; active / inactive periods must be tailored to } \\
\text { the application-specific requirements, which can be further subdivided. They are related to the } \\
\text { medium access protocol. Examples: 1. Techniques centered on selecting active nodes in WSN; } \\
\text { 2. Techniques that perform the ON / OFF mode of active node radios when communication } \\
\text { involves the node. }\end{array}$ \\
\hline Topology control & $\begin{array}{c}\text { Adjusts transmission power, maintaining network connectivity; a low topology is created based on } \\
\text { local information. }\end{array}$ \\
\hline
\end{tabular}

Table 5 Techniques influence on WSN processes

\begin{tabular}{|c|c|c|c|c|c|c|c|}
\hline Stage & $\begin{array}{c}\text { Sensing - } \\
\text { Processing }\end{array}$ & Communication & Collision & Over-Listening & $\begin{array}{c}\text { Package } \\
\text { Control }\end{array}$ & $\begin{array}{c}\text { Passive } \\
\text { Listening }\end{array}$ & Interference \\
\hline Techniques & Major & Major & Secondary & Secondary & & Secondary \\
\hline Data Reduction: & & Major & Secondary & Secondary & Major & Secondary \\
\hline $\begin{array}{c}\text { Efficiency } \\
\text { Routing }\end{array}$ & & Major & Secondary & Major & Secondary & Major \\
\hline Cycle of service & Major & Major & Major & Major & Secondary & Major & Major \\
\hline Topology control & & Major & Major & Major & & Major \\
\hline
\end{tabular}

\subsection{Related work}

WS development has facilitated the emergence of increasingly diverse applications. However, the issue of energy and how to maximize the life of the network in a very limited budget of energy, are still the design priorities.

As we have shown in Table 4, five main classes are considered energy-consuming. Next, there are mentioned the techniques that address the energy efficiency challenge in the literature, divided into the five classes corresponding to Table 4; a brief reference will also be mentioned.

A. Regarding Data Reduction - literature proposals are divided into 3 main categories depending on the data processing stage: Acquisition, Processing, and Communication.

B. Regarding Protocols Size - Schemes to reduce the size of protocols and implicitly their costs, lead ultimately on saving the limited energy resources.

C. Regarding Efficiency routing - raises problems with the design of routing protocols for a network; they seek load balancing, minimizing energy consumption for end-to-end transmission of a packet, avoiding low-energy nodes.

D. Regarding Cycle of service - are techniques for planning activity alternating the active and inactive periods to turn off the radio subsystem whenever possible, and providing an operational network for application.

E. Regarding Topology control algorithms - refers to building and maintaining a low topology that preserves energy while maintaining network connectivity and coverage as shown in [9]. There is an optimum distance transmission that minimizes energy dissipation while keeping a connected topology, as shown in [10]; methods presented in [11] are listed. In Table 6 we made a brief review of data reduction solutions for earlier mentioned classes, as we have found in papers. 
Table 6 State of the art in energy consumption reduction

\begin{tabular}{|c|c|c|c|}
\hline $\begin{array}{l}\text { Main } \\
\text { classes }\end{array}$ & Processing Steps & Techniques & Achievements \\
\hline \multirow{5}{*}{$\begin{array}{l}\text { A Data } \\
\text { Reduction }\end{array}$} & \multirow[b]{2}{*}{ Data acquisition } & 1. Based on sampling & [12-15] \\
\hline & & 2. Based on prediction & $\begin{array}{l}\text { In [16] centralized prediction; in [17] } \\
\text { prediction is done by grouping sensors; in } \\
\text { [18] describes the communication } \\
\text { protocol with neighbors. }\end{array}$ \\
\hline & \multirow[b]{2}{*}{ Data processing } & 1. Data Compression & $\begin{array}{c}\text { Several techniques: Command encoding; } \\
\text { Pipe-line or Dis31bution Compression, in } \\
\text { [19]. }\end{array}$ \\
\hline & & \multirow[t]{2}{*}{ 2. Data aggregation } & $\begin{array}{l}\text { Categories: Structure cluster cu protocols } \\
\text { LEACH in [20-21], PEGASIS in [22]; } \\
\text { Structure tree with the algorithm } \\
\text { appointed DCTC in [23-24]; in [25] low } \\
\text { cost tree; in [26] and in [27], based SMT } \\
\text { and MST. Without structure, in [28] for } \\
\text { dynamic events, or ToD in [29], a scalable } \\
\text { technique. }\end{array}$ \\
\hline & Data transmission & & $\begin{array}{l}\text { They are related to data acquisition and } \\
\text { processing techniques. }\end{array}$ \\
\hline $\begin{array}{c}\text { Main } \\
\text { classes }\end{array}$ & Reduction method & Techniques & Achievements \\
\hline \multirow{10}{*}{$\begin{array}{l}\text { B } \\
\text { Protocols } \\
\text { Size }\end{array}$} & \multirow{2}{*}{$\begin{array}{l}\text { Through regular adaptive } \\
\text { transmission }\end{array}$} & $\begin{array}{l}\text { 1. Based on adaptation to } \\
\text { network changes }\end{array}$ & $\begin{array}{l}\text { In [30], it is suggested to adapt the } \\
\text { message period to network stability. In } \\
\text { [31] Trickle algorithm presents a more } \\
\text { complex approach. }\end{array}$ \\
\hline & & $\begin{array}{l}\text { 2. Based on distance adaptation } \\
\text { to the information source. }\end{array}$ & $\begin{array}{l}\text { In [32] basic idea is the concept Fish Eye } \\
\text { and the period of transmission increases } \\
\text { with distance from the source. }\end{array}$ \\
\hline & \multirow{5}{*}{ By stratified optimization } & 1. Top-down approach & \multirow{5}{*}{$\begin{array}{l}\text { All techniques listed for sensors with } \\
\text { limited resources were given in [33]. }\end{array}$} \\
\hline & & 2. The bottom-up approach & \\
\hline & & 3. Apps-centered approach & \\
\hline & & 4. MAC-centered approach & \\
\hline & & 5. Integrated approach & \\
\hline & \multirow{3}{*}{ By optimizing floods } & 1. Based on multiple relocations & $\begin{array}{l}\text { It has been found to be more difficult to } \\
\text { find for most graphs a set of minimally } \\
\text { connected nodes [34]. }\end{array}$ \\
\hline & & $\begin{array}{l}\text { 2. Based on Dominant Domains } \\
\text { (DD) }\end{array}$ & $\begin{array}{l}\text { In [35-37] a heuristic distribution is used, } \\
\text { where a dominant set is originally built } \\
\text { and then redundant nodes are removed. } \\
\text { Other authors, [38-39], use a leading node } \\
\text { to assign a rank to each node. }\end{array}$ \\
\hline & & $\begin{array}{l}\text { 3. Based on Neighborhood } \\
\text { Negotiations }\end{array}$ & $\begin{array}{l}\text { In [40], any data is described by a } \\
\text { descriptor called metadata, which is } \\
\text { unique and shorter than actual data. }\end{array}$ \\
\hline $\begin{array}{c}\text { Main } \\
\text { classes }\end{array}$ & Reduction method & Techniques & Achievements \\
\hline \multirow{7}{*}{$\begin{array}{l}\text { C } \\
\text { Efficiency } \\
\text { routing }\end{array}$} & \multirow{3}{*}{ By Data-Driven Protocols } & Technology SPIN & [40] \\
\hline & & $\begin{array}{l}\text { Directed Diffusion Technique } \\
(\mathrm{DiD})\end{array}$ & {$[22]$} \\
\hline & & Technology CADR, COUGAR. & {$[22]$} \\
\hline & \multirow{4}{*}{ By hierarchical protocols } & Technology LEACH & {$[22]$} \\
\hline & & Technology PEGASIS & {$[22]$} \\
\hline & & Technology TEEN & {$[22]$} \\
\hline & & Technology APTEEN & [22] \\
\hline
\end{tabular}


Table 6 State of the art in energy consumption reduction (continued)

\begin{tabular}{|c|c|c|c|}
\hline $\begin{array}{l}\text { Main } \\
\text { classes }\end{array}$ & Reduction method & Techniques & Achievements \\
\hline \multirow{5}{*}{$\begin{array}{l}\text { C } \\
\text { Efficiency } \\
\text { routing }\end{array}$} & \multirow{3}{*}{ By Geographic Protocols } & Technology GEAR & [22] \\
\hline & & Technology GAF & {$[22]$} \\
\hline & & Technology SPEED & {$[20]$} \\
\hline & \multirow[b]{2}{*}{ By Opportunistic Protocols } & $\begin{array}{c}\text { Based on spatial and natural } \\
\text { diversity. }\end{array}$ & [41] \\
\hline & & Based on mobility. & $\begin{array}{l}\text { - Variants based on router node mobility } \\
\text { protocols are proposed in [42-45]. } \\
\text { - Protocols based on mobile relays are in } \\
\text { [46-48]. }\end{array}$ \\
\hline $\begin{array}{c}\text { Main } \\
\text { classes }\end{array}$ & Reduction method & Techniques & Achievements \\
\hline \multirow{6}{*}{$\begin{array}{l}\text { D Cycle } \\
\text { of service }\end{array}$} & \multirow{3}{*}{ High level Granularity } & Linear programming technique. & [49-50] \\
\hline & & GAF technique & [22] \\
\hline & & SPAN technique & {$[51-54]$} \\
\hline & \multirow{3}{*}{ Low level Granularity } & $\begin{array}{l}\text { Based on "Time Division } \\
\text { Multiple Access" (TDMA) }\end{array}$ & $\begin{array}{l}\text { Proposed in: [55]-TRAMA; } \\
\text { [56]-FLAMA; [57]-FlexiTP; [58]-ASAP. }\end{array}$ \\
\hline & & $\begin{array}{c}\text { Based on "Sensor Media Access } \\
\text { Control" (SMAC) }\end{array}$ & $\begin{array}{l}\text { Variants: [59]-SYNC messages; } \\
\text { [60]-SMAC; [61]-DMAC; [62]-BMAC. }\end{array}$ \\
\hline & & $\begin{array}{l}\text { Hybrid between TDMA and } \\
\text { "Carrier Sense Multiple Access" } \\
\text { (CSMA) }\end{array}$ & $\begin{array}{c}\text { Variants: [63]- ZMAC; [64] protocol } \\
\text { TDMA/CA based on colors nodes } \\
\text { provided by SERENA }\end{array}$ \\
\hline $\begin{array}{l}\text { Main } \\
\text { classes }\end{array}$ & Reduction method & Techniques & Achievements \\
\hline \multirow{3}{*}{$\begin{array}{c}\mathrm{E} \\
\text { Topology } \\
\text { control } \\
\text { algorithms }\end{array}$} & Directed LMST (DLMST) & DLMST & [11] \\
\hline & Directed RNG (DRNG) & DRNG & [11] \\
\hline & $\begin{array}{l}\text { Residual Energy Aware } \\
\text { Dynamic (READ) }\end{array}$ & READ & {$[11]$} \\
\hline
\end{tabular}

On the other hand, researchers have developed systems with different design hardware, performing the same task. We focused on real-time detection for location and speed, and in addition, the vehicle temperature and to require the imposition of new features and constraints on the measured parameters.

Industry has developed around an ever-changing technology with a wide range of applications aimed at the environment, health systems, military and robotics, as we have shown in Table 6. Typically, such applications use a large number of nodes in a self-organizing multi-hop WSN, running on batteries and equipped with one or more sensors, as well as low power processors and transceivers.

In this section we analyzed the main factors who contributes on reduction of WSN's autonomous operation time, the factors that influence the architecture of the networks, the energy problems that may occur and the State-of-the-Art achievements in the field; we have also developed a classification of energy efficiency techniques by describing the algorithms that lead to the reduction of energy consumption which were synthesized in Table 6. In addition, for a complete analysis of real-time tracking devices, we recommend to the interested readers to consult Chapter3 from reference [65].

Instead of conclusions: It is obvious that the domain is still open to researchers, the subject of consumption and limited resources over time being more present than ever.

\section{Hardware Development}

A node consumes energy and most of it, with values between $60 \%$ and $80 \%$ [66-67], during communication. At the same time improving energy storage has an annual average growth rate of $6 \%$, as stated in [68]. Due to many constraints, the 
complexity of nodes development is limited. Depending on applications, nodes can be designed with enhanced local decision capacity or not.

As we pointed out in the introduction, the paper presents the evolution of our own WS, with GPS - GSM/GPRS features; the design and improvement criterion were the stand-alone operating time by reducing energy consumption. Our focus is on both hardware and software sides, and Figs. 3-5 show the evolution on the hardware enhancement component. As can be seen, the large number of physical components in Fig. 3 led to a reconsideration in the design concept (see Figs. 4 and 5).

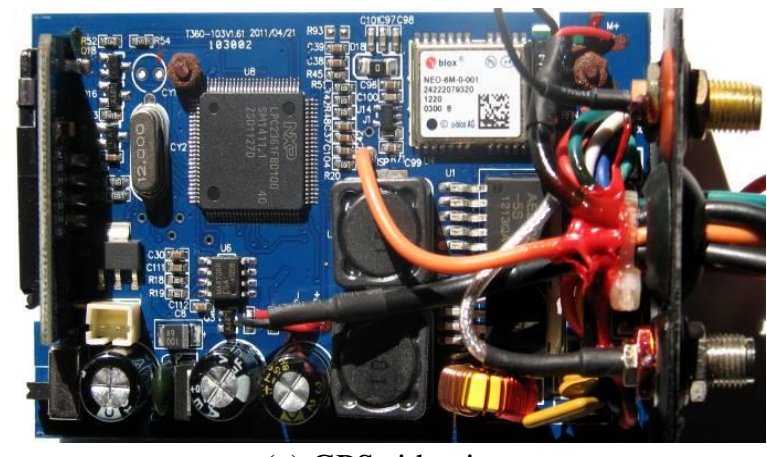

(a) GPS side view

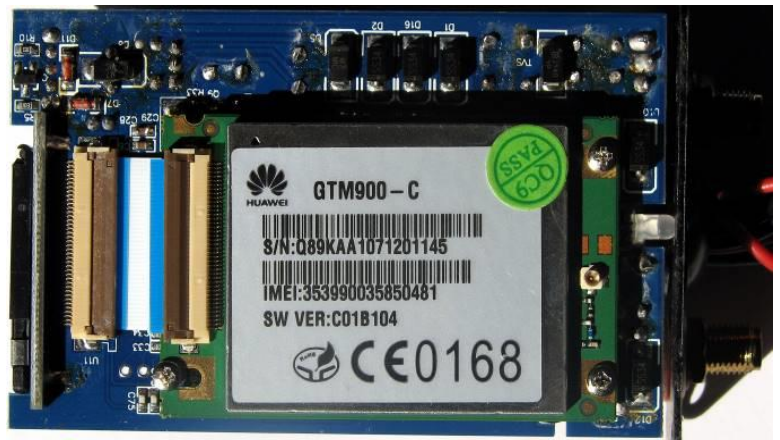

(b) GSM/GPRS side view

Fig. 3 First hardware solution

The demand for choosing the electronic components in the following modules was reported in the energy consumption balance of the active components (see Appendix 2 with datasheet reference).

Overall the entire hardware system, besides module from this work, includes the following units:

(1) The mobile units specialized in "machine to machine", tracking;

(2) The alarm station;

(3) Hardware systems to optimize energy consumption and battery charge that ensures autonomy of WS;

(4) Hardware analysis and filtering systems for analogue and/or digital signals.

The module is based on the dual GPS-GSM/GPRS connection, and performs remote positioning and target monitoring via SMS or Internet; it has statistical features for mileage, detection and alarm when power is interrupted, as well as other customizable features. External interfaces make it possible to connect a Radio Frequency Identifier (RFID), to a serial port, a fuel sensor, an LED display, etc.

The modules in this paper have been modified for improved performance particularly energy consumption and thus increase autonomy in operation. However, they need to be explained as follows:

Fig. 3 shows the first prototype, made on double front wiring, one dedicated to GPS communications (Fig. 3(a)), the other side to GSM communications (Fig. 3(b)). As a result of increasing number of simultaneous surveillance and different manufacturers for GPS and GSM modems (GPS-U-Blox, GSM-Huawei, CPU-Philips), rewriting of the programs in modules according to the adaptations needed for the transmission and reception was not fully compatible and satisfactorily, optimization and technical compatibility not being $100 \%$ possible at that time. In addition to this variant we didn't take into account the optimization of the data transmission, the main requirement being the stability of the transmission and its non-stop maintenance. In an analysis of the total energy consumption, we found that it exceeded $250 \mathrm{~mA} / \mathrm{h}$, which, subject to the requirement of autonomy, was limited to a maximum of 24 hours.

Fig. 4 it is the intermediate step of improving the first module, in the sense of redesigning the double-sided wiring, the use of the same manufacturer for GPS and GSM modems and an Advanced RISC Machine (ARM) microprocessor ( $\mu$ P). 


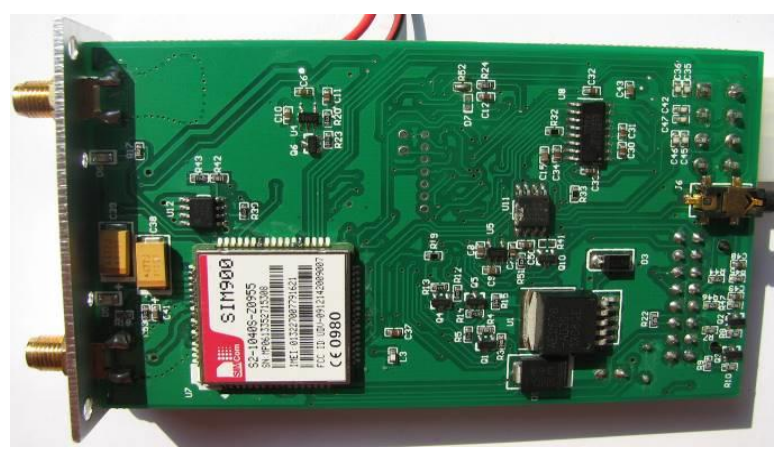

Fig. 4 The second hardware solution

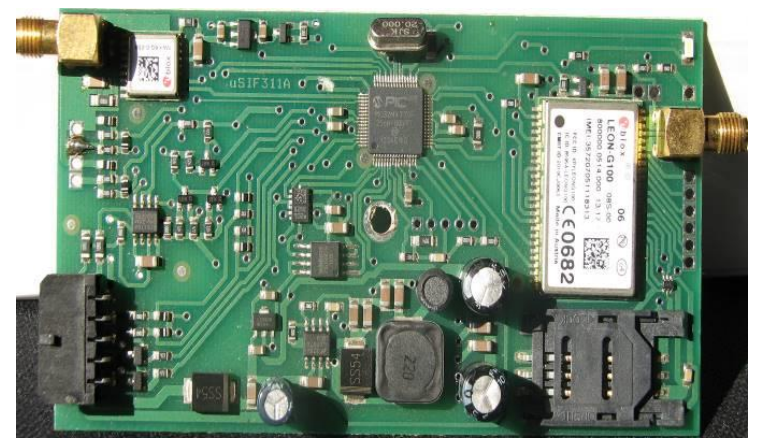

Fig. 5 The third hardware solution

However, there were several drawbacks related to energy consumption (80mA max GSM modem / h, max 30mA GPS / h and $\mu \mathrm{P} \max 15 \mathrm{~mA} / \mathrm{h}$ relative to a supply voltage of $3.3 \mathrm{~V}$ ), but also in local limitation at $\mu \mathrm{P}$ level of data processing before the transmission, and with this version we have succeeded, within 30 days, to deliver without loss of quality and accuracy, only $5 \mathrm{MB}$ of data, thanks to software development supported by $\mu \mathrm{P}$. Full description can be found in [5]. Since energy efficiency remains the main theme, we continued to improve the module at hardware point of view.

Fig. 5 represents the new hardware concept that improves the life of its own power supply (if it is used to continuously track container shipping). Also, through a physical interface, it can be linked to a hardware and software management interface for data and alarms transmission and reception, thus becoming a coordinating node in a network topology. The design concept is also a double face circuit, the two components responsible for the GPS-GSM/GPRS communication are from U-blox with a consumption of $5 \mathrm{~mA} / \mathrm{h}$ in stand-by; entire assembly consumes $75 \mathrm{~mA} / \mathrm{h}$ in transmission-reception mode, which satisfies one of the objectives stated in paper. Equipped with a $\mu \mathrm{P}$ from Microchip (PIC32MX775) with a Core 80MHz/32-bit MIPS 105DMIPS M4K ${ }^{\circledR}$ [69], we were able to write a program to detect all events that required a "wake-up" decision from SLEEP mode, to perform all instructions for data transmission or reception, consumption in SLEEP mode being determined insignificant $(5 \mathrm{~mA})$.

Another aspect of hardware design, as we have already noted, is the quality of the active components used; so, using the processor at a minimum computing power and working frequency, the results are reflected in improving the overall energy balance because, as we said, energy consumption increase with increasing work frequency and computing power.

\section{The Software Application}

Table 7 Loop code distribution [5]

\begin{tabular}{|c|c|}
\hline Original Code & Modified Code \\
\hline 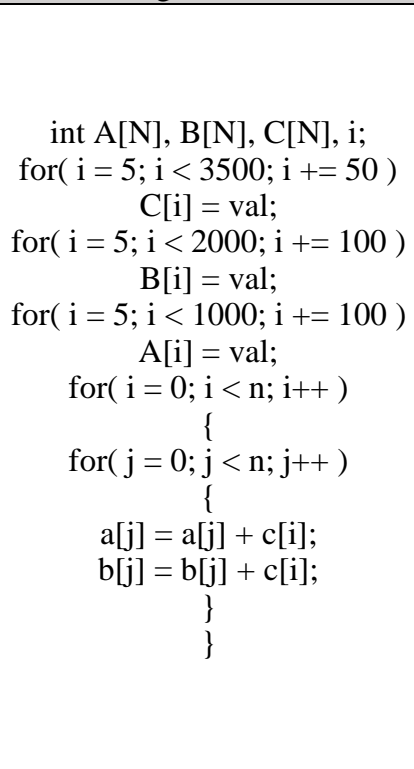 & 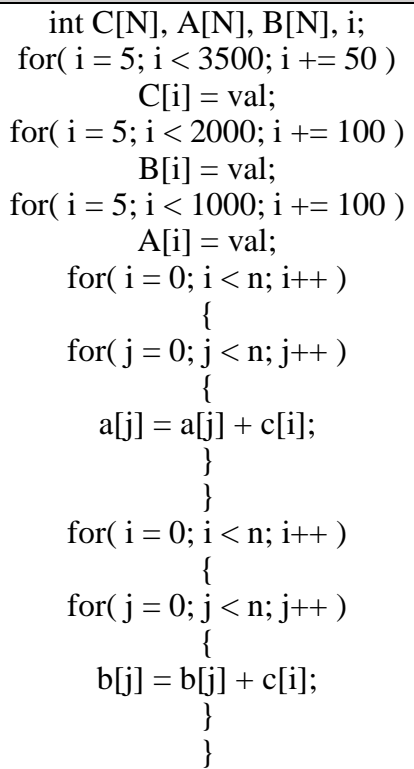 \\
\hline
\end{tabular}


Allows mobile units to be viewed by using maps; the resident program in mobile units GPS/GSM/GPRS or GSM/GPRS is written in the programming language $\mathrm{C} / \mathrm{C}++/$ Java, while for the communications server we only used the Java programming language. Both programs, from mobile units and communication server, perform specific functions.

Simultaneously, for the remote data transfer algorithm we focused on minimizing the number of usable bits in data packets; next data packet is transmitted or not, depending on the decision taken locally in WS, the decision being in fact only on the data difference calculated by the sensor between the transmitted and the current packet. Such transmission duty cycle is shortened, leading to a decrease in the sensor energy effort.

A very useful method to decrease energy consumption is also optimizing the code. As we shown in [5], there are many optimization techniques; of all of them, we expose to the reader a modified programing code solution so that it will require a minimum CPU usage (see Table 7) [5].

The costumed software solutions call a few tricks and even though at first glance it gives the impression that it is laborious; in its decipherment it can be seen that by intelligent use of structured programming blocks that accelerates work instructions specific to the programming language (interrupts, semaphores, timers, reducing execution time, loops technique by vector addition and distribution loops, reducing the instantaneous power, cache memory usage, storage 0 instead of 1), simultaneously with tailored software solutions that minimize transmission time (special protocols, data compression, eliminate transmission errors, choosing optimal level of security), the use of CPU is directed to the minimum calculations required.

\section{GPS Tracking System}

Real-time tracking with one of the modules described in Section 3, are made according to the diagram in Fig. 6: Internet access to the system is via web/ftp servers that are loaded with a series of html pages containing "server-side" scripts and "client-side" scripts, which are actually files such as XML, CSS, SWF, etc.

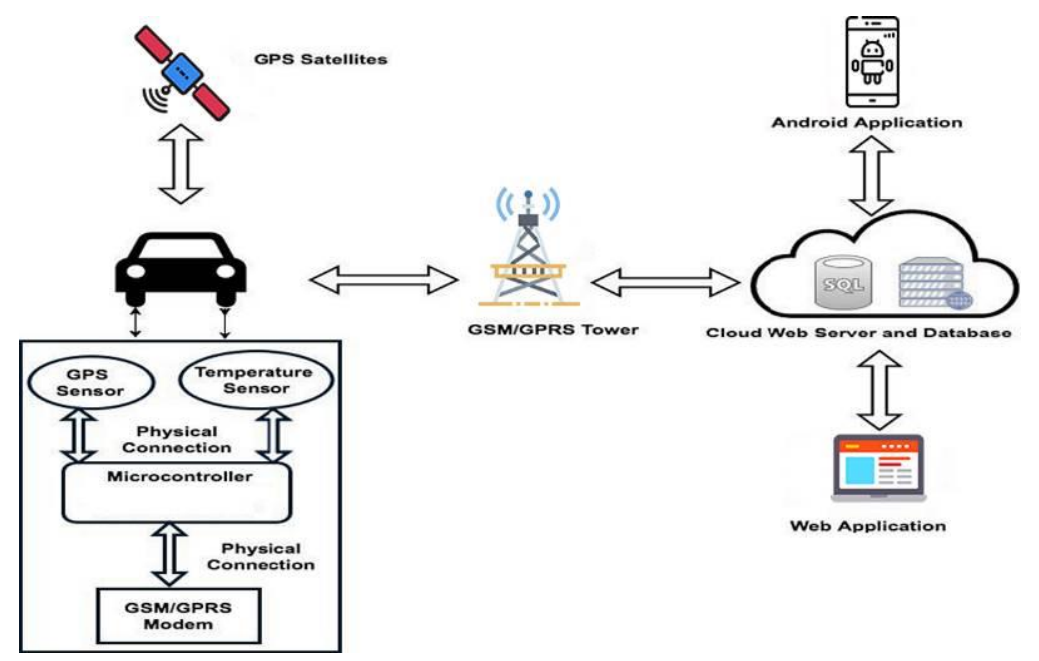

Fig. 6 Real-time GPS tracking system

Note: Alarms generated by mobile units or fixed GPRS communicators are transmitted by dual GPRS / GSM; so we have the guarantee that the alarms will be dispatched regardless of the provider's GSM / GPRS network; in this way the success rate can be up to $100 \%$.

We remind that GPS tracking uses the global satellite network, while GSM / GPRS mobile terrestrial network. These servers are designed and configured so that they can perform certain functions:

(1) To communicate bidirectionally with Java servers through: Commands, Messages, Events, GPS positions, Data Base (DB) information etc., with the purpose of mediating customer-car links. 
(2) Communicate with DB to get mobile unit reports, DB personalization by customers, viewing routes, positions, on-line journeys, points of interest, areas of interest, events, etc.

(3) Communicate with other users (customers, operators, administrators, etc.) through programs that are localized to the administrator or clients, for mobile unit management, back-ups, log management, etc.

(4) To configure, display and maintain the maps functionality.

(5) To execute the Download Over the Air (DOTA) operation through FTP protocols.

(6) Ensure the possibility of on-line uploading, directly by clients, of back-up files.

\subsection{The software system}

Enables mobile units to be viewed using maps, which have the following features:

(1) Vectorized format, which makes their size to be very small (under 100KB each).

(2) They are always on the client's computer, so they "move very fast" to any mouse action (zoom, left / right, up / down).

(3) Objects displayed on the map are disjoint, so size map remains the same no matter how many items are displayed on this.

(4) Both the server and client computer information, can be displayed on a map, at the same time.

(5) At any change of displayed information, the map remains the same, the refresh sensation being insensible.

(6) Regardless of users' number accessing the same map, it will "move" as fast as it would on the client's computer.

(7) The map can display simultaneously in real time, approx. 1000 (one thousand) cars.

(8) Maps can be displayed on any PC, Laptop, PDA or Smart Phone.

(9) Any change in the field will be done very quickly on the appropriate maps, because the software required for editing and georeferencing is proprietary.

(10) It can compile a map in its own format for any city in the world in a few days.

(11) Each map has an associated chart network (corresponding to the access paths) through which may represent routes or find optimal paths between points; the software needed to create this network as proprietary code.

(12) Georeferencing of maps is also done using proprietary software code.

(13) Access to information is the rule type user / password / rights.

(14) Optional, it can be implemented and viewed on Google Maps; on request, any public maps, for which the client provides user IDs (Yahoo, Open street, Garmin, Google etc.), can be used.

As practical implementation at national level, we scaled Romania map at 1: 25,000, being able to realize various views (e.g. view by time and geographic area).

\subsection{Fleet/machine to machine monitoring}

Typically, the tracking unit program algorithm passes through three steps: measuring, recording and transmitting data over the GSM network; maximum power consumption is recorded in the last round when data is transmitted via GSM network.

To reduce energy consumption, the workflow implemented on the tracking unit goes through five stages. To the three steps mentioned we introduced two more sequences, memorize and compare, designed to reduce data transmission stage. 
How it works? In the step memorizes, $\mu \mathrm{P}$ stores the output of the sensors as variables in its memory; then in compare step, the new values of the acquired data are compared with those in the previous step. Ex.: For geographical azimuth (latitude and longitude) the new values measured are compared with those already previously stored; if they are identical, then compare other physical values (temperature): If the difference between two consecutive measurements does not exceed a default threshold, then the data is not transmitted, otherwise the data is transmitted.

Monitoring is done in real time, data transmission from the mobile unit to the servers being made by GPS / GSM / GPRS continuously $24 \mathrm{~h} / 7$ days. Pseudocode algorithm that guide in 5 steps shows as follows:

Measures temperature, position and speed;

If position is identical to the previous position;

If temperature is identical to the previous temperature;

If the difference between the previous temperature and the current temperature is within the threshold;

Do not transmit data;

Else transmit data;

Else transmit data;

For more detailed analyzes, besides the website, there is a special monitoring software with capabilities in car behavior analysis. Alarms generated by mobile units or fixed GPRS communicators are transmitted dual GSM / GPRS.; success rate of alarms as they reach dispatch center, regardless of mobile communication network GSM / GPRS, is approaching by $100 \%$.

The application runs on any computer with Internet connection and Windows. A large number of monitors can be installed and this does not affect system load, or limit real-time access to monitored vehicles or fixed targets; a remote tracking application we also described in [70] The main interface of the Screen control, is divided into two divisions:

- Self-monitoring track division and

- The alarms monitoring division from either monitored vehicles or fixed targets

Viewing mobile units is done using maps that provide information about mobile unit positions in several variants: routes, current positions, all in real time, for groups or subgroups of cars, or individual cars in any of the above-mentioned variants.

Note: All programs that use maps are proprietary code and maps are loaded in vector format from Google Maps!

\subsection{System maintenance}

For system maintenance, a series of dedicated programs are used, that perform database management functions, traffic analysis, information stored in the system, georeferencing, associated network drawing maps, server monitoring and backup. These are able to perform both functions of management activities, as well as analysis and providing reports; Figs. 7 and 8 are such examples for database management functions. These mean the following: Fig. 7 is a report generated for a car for 24 hours.

The upper part is a complete report, while the two-column table is the synthesis of the day. Fig. 8 is a 24 hours summary for a client who owns a fleet of 27 cars; green means stationary, blue stops, and movement ocher. In addition, Fig. 8 has a "Blind Zone" column, which means that the vehicle could not be located by GPS. The other data are easy to understand. 


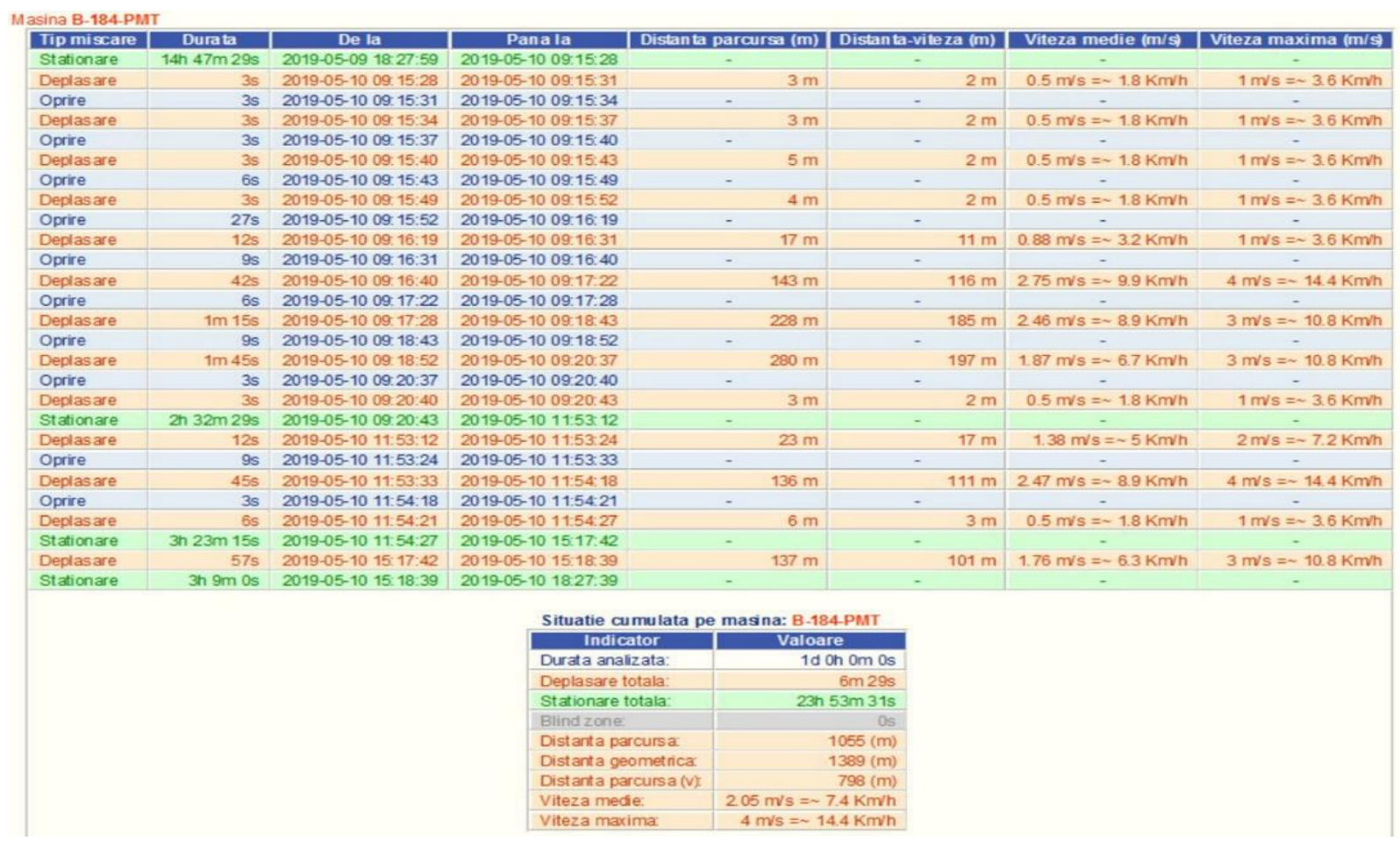

Fig. 7 Real-time GPS detailed report for one car

Sinteza

\begin{tabular}{|c|c|c|c|c|c|c|c|c|}
\hline Masina & Deplasare totala & Stationare totala & Blind zone & Distanta parcursa & Distanta geometrica & Distanta parcursa (v) & Viteza medie & Viteza maxima \\
\hline B.100-MTP & $1 \mathrm{~m} \mathrm{25s}$ & $23 \mathrm{~h} 55 \mathrm{~m} 55 \mathrm{~s}$ & $2 \mathrm{~m} 40 \mathrm{~s}$ & $95(\mathrm{~m})$ & $964(\mathrm{~m})$ & $87(\mathrm{~m})$ & $1.02 \mathrm{~m} / \mathrm{s}=\sim 3.7 \mathrm{Km} / \mathrm{h}$ & $5 \mathrm{~m} / \mathrm{s}=\sim 18 \mathrm{Km} / \mathrm{h}$ \\
\hline B-100-PMI & $5 \mathrm{~h} 54 \mathrm{~m} 22 \mathrm{~s}$ & $18 \mathrm{~h} 5 \mathrm{~m} 38 \mathrm{~s}$ & Os & $356608(\mathrm{~m})$ & $357683(\mathrm{~m})$ & $336257(\mathrm{~m})$ & $15.81 \mathrm{~m} / \mathrm{s}=\sim 56.9 \mathrm{Km} / \mathrm{h}$ & $25 \mathrm{~m} / \mathrm{s}=\sim 90 \mathrm{Km} / \mathrm{h}$ \\
\hline B-107-PMT & $7 \mathrm{~m} 42 \mathrm{~s}$ & $23 \mathrm{~h} 52 \mathrm{~m} 18 \mathrm{~s}$ & Os & $1111(\mathrm{~m})$ & $1436(\mathrm{~m})$ & $717(\mathrm{~m})$ & $1.55 \mathrm{~m} / \mathrm{s}=\sim 5.6 \mathrm{Km} / \mathrm{h}$ & $4 \mathrm{~m} / \mathrm{s}=\sim 14.4 \mathrm{Km} / \mathrm{h}$ \\
\hline B-11.PMT & $35 \mathrm{~m} \mathrm{17s}$ & $23 \mathrm{~h} 24 \mathrm{~m} 43 \mathrm{~s}$ & os & $14906(\mathrm{~m})$ & $15243(\mathrm{~m})$ & $13140(\mathrm{~m})$ & $6.21 \mathrm{~m} / \mathrm{s}=\sim 22.3 \mathrm{Km} / \mathrm{h}$ & $16 \mathrm{~m} / \mathrm{s}=\sim 57.6 \mathrm{Km} / \mathrm{h}$ \\
\hline B-112.PMI & $1 \mathrm{~h} 10 \mathrm{~m} \mathrm{30s}$ & $22 \mathrm{~h} 46 \mathrm{~m} 45 \mathrm{~s}$ & $2 m 45 s$ & $31085(\mathrm{~m})$ & $31861(\mathrm{~m})$ & $27692(m)$ & $6.55 \mathrm{~m} / \mathrm{s}=-23.6 \mathrm{Km} / \mathrm{h}$ & $14 \mathrm{~m} / \mathrm{s}=\sim 50.4 \mathrm{Km} / \mathrm{h}$ \\
\hline B-114.PMI & 1h $12 \mathrm{~m} 21 \mathrm{~s}$ & $22 \mathrm{~h} 47 \mathrm{~m} 39 \mathrm{~s}$ & Os & $31945(\mathrm{~m})$ & $33315(\mathrm{~m})$ & $28426(\mathrm{~m})$ & $6.55 \mathrm{~m} / \mathrm{s}=\sim 23.6 \mathrm{Km} / \mathrm{h}$ & $24 \mathrm{~m} / \mathrm{s}=\sim 86.4 \mathrm{Km} / \mathrm{h}$ \\
\hline B-115.PMT & $1 \mathrm{~h} 2 \mathrm{~m} 36 \mathrm{~s}$ & $22 \mathrm{~h} 57 \mathrm{~m} 24 \mathrm{~s}$ & os & $33394(\mathrm{~m})$ & $34545(\mathrm{~m})$ & $29233(\mathrm{~m})$ & $7.78 \mathrm{~m} / \mathrm{s}=\sim 28 \mathrm{Km} / \mathrm{h}$ & $22 \mathrm{~m} / \mathrm{s}=\sim 79.2 \mathrm{Km} / \mathrm{h}$ \\
\hline B.122.PMT & $3 \mathrm{~h} 32 \mathrm{~m} 51 \mathrm{~s}$ & $20 \mathrm{~h} 27 \mathrm{~m} \mathrm{9s}$ & Os & $169913(\mathrm{~m})$ & $171459(\mathrm{~m})$ & $158403(\mathrm{~m})$ & $12.4 \mathrm{~m} / \mathrm{s}=\sim 44.7 \mathrm{~km} / \mathrm{h}$ & $39 \mathrm{~m} / \mathrm{s}=-140.4 \mathrm{Km} / \mathrm{h}$ \\
\hline B.123.PMT & 1h $57 \mathrm{~m} 37 \mathrm{~s}$ & $22 \mathrm{~h} 2 \mathrm{~m} 23 \mathrm{~s}$ & os & $53392(\mathrm{~m})$ & $54826(\mathrm{~m})$ & $48203(\mathrm{~m})$ & $6.83 \mathrm{~m} / \mathrm{s}=\sim 24.6 \mathrm{Km} / \mathrm{h}$ & $22 \mathrm{~m} / \mathrm{s}=\sim 79.2 \mathrm{Km} / \mathrm{h}$ \\
\hline B-124.PMT & & & $1 \mathrm{~d} 0 \mathrm{~h} 0 \mathrm{~m} \mathrm{0s}$ & - & - & - & - & - \\
\hline B-148-PMT & $3 \mathrm{~m} 17 \mathrm{~s}$ & $23 \mathrm{~h} 56 \mathrm{~m} 43 \mathrm{~s}$ & os & $579(\mathrm{~m})$ & $779(\mathrm{~m})$ & $394(\mathrm{~m})$ & $2 \mathrm{~m} / \mathrm{s}=-7.2 \mathrm{Km} / \mathrm{h}$ & $5 \mathrm{~m} / \mathrm{s}=\sim 18 \mathrm{Km} / \mathrm{h}$ \\
\hline B.150-MTP & $23 \mathrm{~m} \mathrm{17s}$ & $23 \mathrm{~h} 34 \mathrm{~m} 17 \mathrm{~s}$ & $2 \mathrm{~m} 26 \mathrm{~s}$ & $10140(\mathrm{~m})$ & $11851(m)$ & $9766(m)$ & $6.99 \mathrm{~m} / \mathrm{s}=-25.2 \mathrm{Km} / \mathrm{h}$ & $16 \mathrm{~m} / \mathrm{s}=-57.6 \mathrm{Km} / \mathrm{h}$ \\
\hline B-175-PMI & $11 \mathrm{~s}$ & $23 \mathrm{~h} 59 \mathrm{~m} 49 \mathrm{~s}$ & $0 \mathrm{~s}$ & $0(m)$ & $67(\mathrm{~m})$ & $0(m)$ & $0 \mathrm{~m} / \mathrm{s}=-0 \mathrm{Km} / \mathrm{h}$ & $0 \mathrm{~m} / \mathrm{s}=\sim 0 \mathrm{Km} / \mathrm{h}$ \\
\hline B-184.PMT & $6 \mathrm{~m} \mathrm{29s}$ & $23 \mathrm{~h} 53 \mathrm{~m} 31 \mathrm{~s}$ & os & $1055(\mathrm{~m})$ & $1389(\mathrm{~m})$ & $798(\mathrm{~m})$ & $2.05 \mathrm{~m} / \mathrm{s}=\sim 7.4 \mathrm{Km} / \mathrm{h}$ & $4 \mathrm{~m} / \mathrm{s}=\sim 14.4 \mathrm{Km} / \mathrm{h}$ \\
\hline B.194.PMI & $5 s$ & $23 \mathrm{~h} 59 \mathrm{~m} 55 \mathrm{~s}$ & Os & $0(m)$ & $308(\mathrm{~m})$ & $0(m)$ & $0 \mathrm{~m} / \mathrm{s}=\sim 0 \mathrm{Km} / \mathrm{h}$ & $0 \mathrm{~m} / \mathrm{s}=\sim 0 \mathrm{Km} / \mathrm{h}$ \\
\hline B-195-PMI & 4h $59 \mathrm{~m} 45 \mathrm{~s}$ & $19 \mathrm{~h} 0 \mathrm{~m} 15 \mathrm{~s}$ & os & $274291(\mathrm{~m})$ & $276372(\mathrm{~m})$ & $256340(\mathrm{~m})$ & $14.25 \mathrm{~m} / \mathrm{s}=\sim 51.3 \mathrm{Km} / \mathrm{h}$ & $23 \mathrm{~m} / \mathrm{s}=\sim 82.8 \mathrm{Km} / \mathrm{h}$ \\
\hline B-20-BLS & $44 \mathrm{~m} 47 \mathrm{~s}$ & $23 \mathrm{~h} 10 \mathrm{~m} 9 \mathrm{~s}$ & $5 \mathrm{~m} \mathrm{4s}$ & $16566(\mathrm{~m})$ & $21534(m)$ & $13838(\mathrm{~m})$ & $5.15 \mathrm{~m} / \mathrm{s}=\sim 18.5 \mathrm{Km} / \mathrm{h}$ & $24 \mathrm{~m} / \mathrm{s}=-86.4 \mathrm{Km} / \mathrm{h}$ \\
\hline B.23.PMT & - & - & $1 \mathrm{~d} 0 \mathrm{~h} 0 \mathrm{~m} \mathrm{0s}$ & - & - & - & - & - \\
\hline B-29-MTP & 3h $14 \mathrm{~m} 44 \mathrm{~s}$ & $20 \mathrm{~h} 45 \mathrm{~m} 16 \mathrm{~s}$ & os & $229988(\mathrm{~m})$ & $230686(\mathrm{~m})$ & $217356(\mathrm{~m})$ & $18.6 \mathrm{~m} / \mathrm{s}=\sim 67 \mathrm{Km} / \mathrm{h}$ & $30 \mathrm{~m} / \mathrm{s}=\sim 108 \mathrm{Km} / \mathrm{h}$ \\
\hline B-333-PMT & $1 \mathrm{~h} 46 \mathrm{~m} 36 \mathrm{~s}$ & $22 \mathrm{~h} 13 \mathrm{~m} \mathrm{24s}$ & os & $55019(\mathrm{~m})$ & $57837(\mathrm{~m})$ & $49349(\mathrm{~m})$ & $7.72 \mathrm{~m} / \mathrm{s}=-27.8 \mathrm{Km} / \mathrm{h}$ & $25 \mathrm{~m} / \mathrm{s}=-90 \mathrm{Km} / \mathrm{h}$ \\
\hline B-38-MTP & 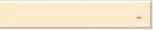 & - & $1 \mathrm{~d} 0 \mathrm{~h} 0 \mathrm{~m} \mathrm{0s}$ & - & - & - & - & - \\
\hline B-42.PMT & $5 s$ & $23 \mathrm{~h} 59 \mathrm{~m} 55 \mathrm{~s}$ & os & $0(\mathrm{~m})$ & $10(\mathrm{~m})$ & $0(\mathrm{~m})$ & $0 \mathrm{~m} / \mathrm{s}=\sim 0 \mathrm{Km} / \mathrm{h}$ & $0 \mathrm{~m} / \mathrm{s}=-0 \mathrm{Km} / \mathrm{h}$ \\
\hline B-44.PMT & $4 \mathrm{~h} 6 \mathrm{~m} 39 \mathrm{~s}$ & $19 \mathrm{~h} 53 \mathrm{~m} 21 \mathrm{~s}$ & os & $268651(\mathrm{~m})$ & $270058(\mathrm{~m})$ & $254227(\mathrm{~m})$ & $17.18 \mathrm{~m} / \mathrm{s}=\sim 61.8 \mathrm{Km} / \mathrm{h}$ & $24 \mathrm{~m} / \mathrm{s}=-86.4 \mathrm{Km} / \mathrm{h}$ \\
\hline B.45.PMT & $7 \mathrm{~s}$ & $23 \mathrm{~h} 59 \mathrm{~m} 53 \mathrm{~s}$ & Os & $0(\mathrm{~m})$ & $195(\mathrm{~m})$ & $0(\mathrm{~m})$ & $0 \mathrm{~m} / \mathrm{s}=\sim 0 \mathrm{Km} / \mathrm{h}$ & $0 \mathrm{~m} / \mathrm{s}=\sim 0 \mathrm{Km} / \mathrm{h}$ \\
\hline B-48-PMT & & - & $1 \mathrm{~d} 0 \mathrm{~h} 0 \mathrm{~m} 0 \mathrm{~s}$ & - & - & - & - & - \\
\hline B-555.PMT & $1 \mathrm{~h} 3 \mathrm{~m} 32 \mathrm{~s}$ & $22 \mathrm{~h} 51 \mathrm{~m} 27 \mathrm{~s}$ & $5 \mathrm{~m}$ 1s & $23574(\mathrm{~m})$ & $28782(m)$ & $24529(\mathrm{~m})$ & $6.43 \mathrm{~m} / \mathrm{s}=-23.2 \mathrm{Km} / \mathrm{h}$ & $15 \mathrm{~m} / \mathrm{s}=-54 \mathrm{Km} / \mathrm{h}$ \\
\hline B.72-MTP & & & $1 \mathrm{~d} 0 \mathrm{~h} 0 \mathrm{~m} 0 \mathrm{~s}$ & - & - & - & - & - \\
\hline B.90.PMT & 4h $17 \mathrm{~m} 5 \mathrm{~s}$ & $19 \mathrm{~h} 42 \mathrm{~m} 55 \mathrm{~s}$ & os & $265246(\mathrm{~m})$ & $265864(\mathrm{~m})$ & $258321(\mathrm{~m})$ & $16.75 \mathrm{~m} / \mathrm{s}=\sim 60.3 \mathrm{Km} / \mathrm{h}$ & $31 \mathrm{~m} / \mathrm{s}=-111.6 \mathrm{Km} / \mathrm{h}$ \\
\hline B-900.PMT & 1h $17 \mathrm{~m} 25 \mathrm{~s}$ & $22 \mathrm{~h} 42 \mathrm{~m} 35 \mathrm{~s}$ & Os & $51583(\mathrm{~m})$ & $52234(\mathrm{~m})$ & $47564(m)$ & $10.24 \mathrm{~m} / \mathrm{s}=\sim 36.9 \mathrm{Km} / \mathrm{h}$ & $23 \mathrm{~m} / \mathrm{s}=\sim 82.8 \mathrm{Km} / \mathrm{h}$ \\
\hline B.93-MTP & $36 \mathrm{~m} 50 \mathrm{~s}$ & $23 \mathrm{~h} 23 \mathrm{~m} 10 \mathrm{~s}$ & os & $16082(\mathrm{~m})$ & $17096(\mathrm{~m})$ & $14337(\mathrm{~m})$ & $6.49 \mathrm{~m} / \mathrm{s}=\sim 23.4 \mathrm{Km} / \mathrm{h}$ & $27 \mathrm{~m} / \mathrm{s}=\sim 97.2 \mathrm{Km} / \mathrm{h}$ \\
\hline B.98-PMT & $15 \mathrm{~s}$ & $23 \mathrm{~h} 59 \mathrm{~m} 45 \mathrm{~s}$ & Os & $0(m)$ & $58(\mathrm{~m})$ & $0(\mathrm{~m})$ & $0 \mathrm{~m} / \mathrm{s}=\sim 0 \mathrm{Km} / \mathrm{h}$ & $0 \mathrm{~m} / \mathrm{s}=\sim 0 \mathrm{Km} / \mathrm{h}$ \\
\hline
\end{tabular}

Fig. 8 Real-time GPS detailed cars report

\section{Experiments and Results}

We have already mentioned in the previous section, that in tracking algorithm we introduced two more intermediate sequences aimed at reducing energy consumption for the device. The determinations were made on two levels: hardware and software. In this section we have summarized the main results.

\subsection{The hardware development}

The experiment was designed to measure the energy consumption of the tracking device. For this purpose, we used the Monsoon Power Monitor (MPM) hardware to determine energy consumption [71], the second and third hardware solution (Figs. 4 and 5), and the appropriate MPM Graphic User Interface (GUI) available at [72], installed on a laptop with an Intel 
Centrino 2 Duo processor, 8GB of RAM, and Windows 10 Pro OS.; the description of GUI software for these measurements is provided also in [71].

The graph GUI scale was set as follows:

(1) Time (bottom) was shown every $100 \mathrm{~ms}$, with 10 units gap.

(2) On left side Power, with a scale gap of $500 \mathrm{~mW}$.

(3) On right side Current, with a scale gap of 500mA.

And the measurements results are shows in Fig. 9.

The battery size was 550mAh, which is for a 9V battery, on display is show the number of samples, the total consumed energy, average power and the average tension for the entire duration of the measurement.

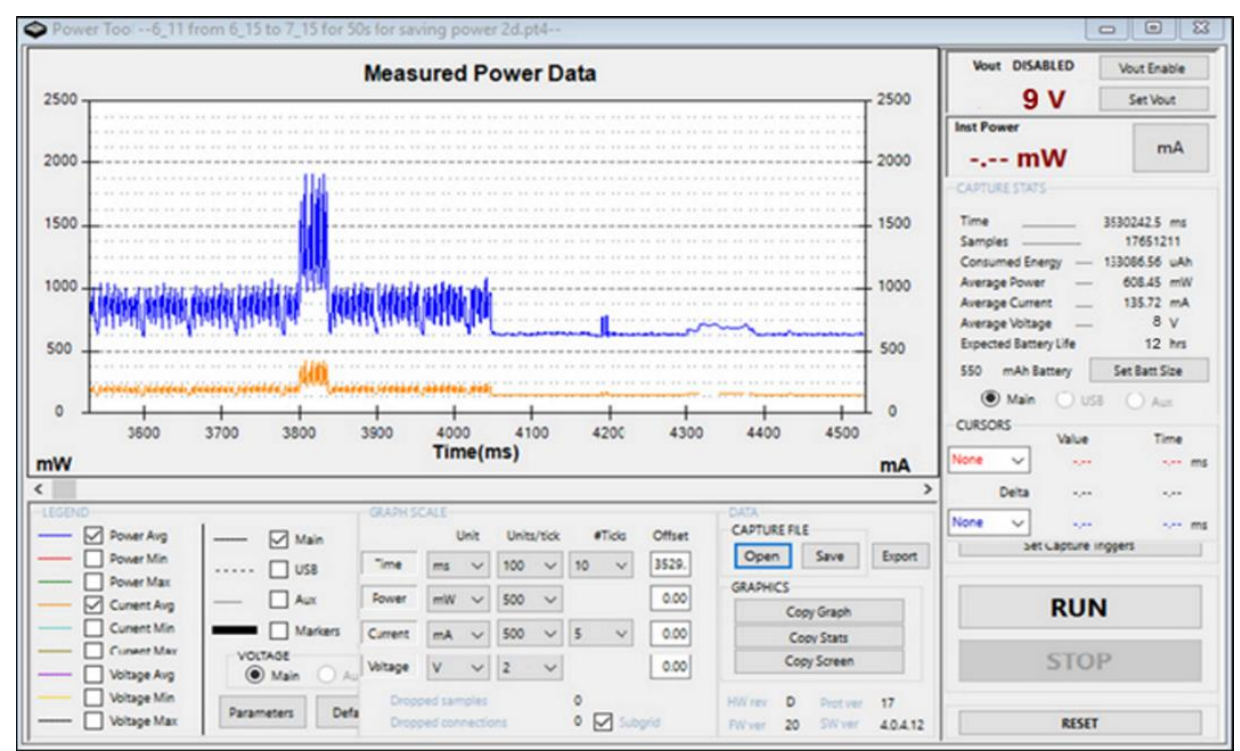

Fig. 9 Power measurements results

\subsection{The software development}

In this section we have summarized the main results for the software applications. The following figures highlight comments made in Sections 4 and 5 of this paper; Fig. 10 is a custom GUI for logging into the GPS tracking system, written as we said in Java.

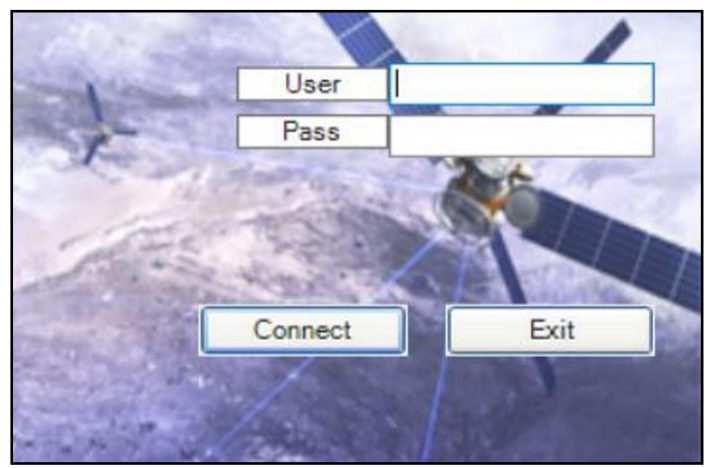

Fig. 10 GUI logging interface

In Section 5 we said that real-time tracking is done by GPS and communication of positions through GSM/GPRS; here too we mentioned that through the proprietary software we were able to build our own tracking maps, with different levels of resolution and accuracy. In Figs. 11-13 maps are carried on 3 levels of accuracy, from general to detail on the area of interest (Fig. 13 is the city of Bucharest). In Fig. 14 we gave a detail plan; is from Faculty of Electronics (we noted). 


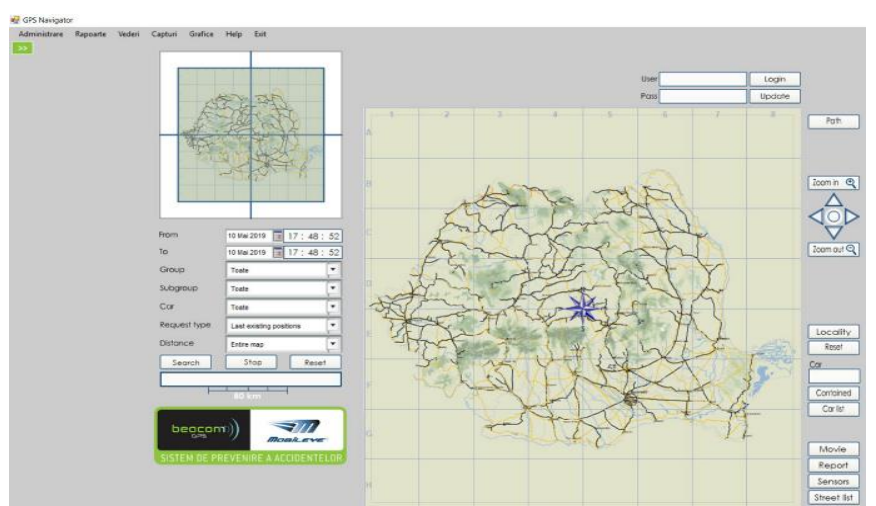

Fig. 11 Level 1 accuracy of own tracking maps

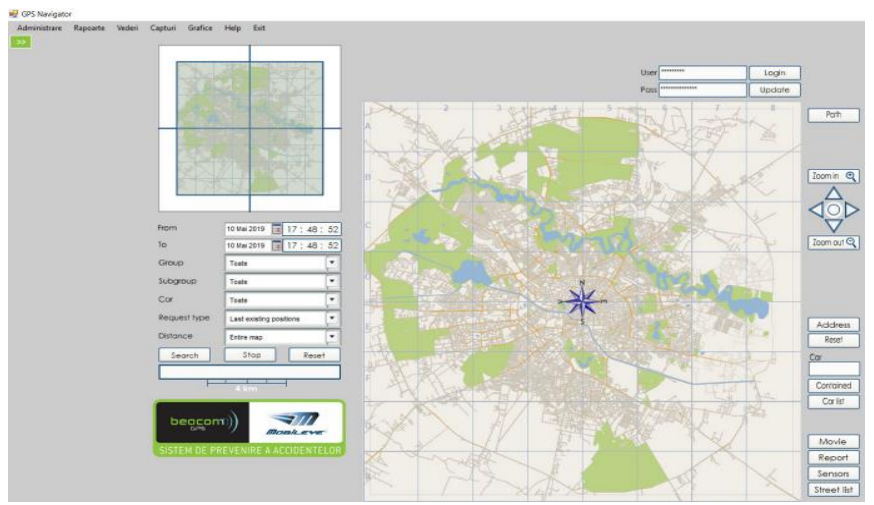

Fig. 13 Level 3 accuracy of own tracking maps

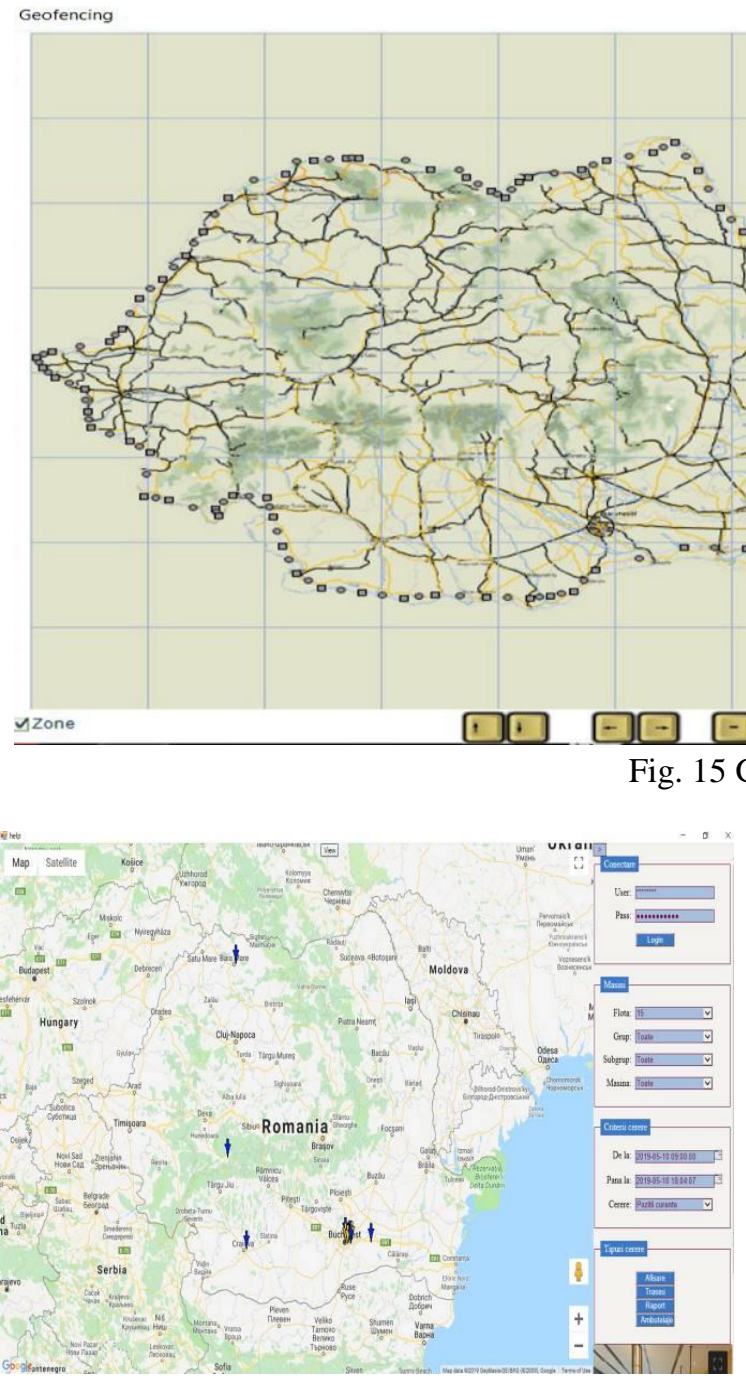

Fig. 16 Real-time position repot

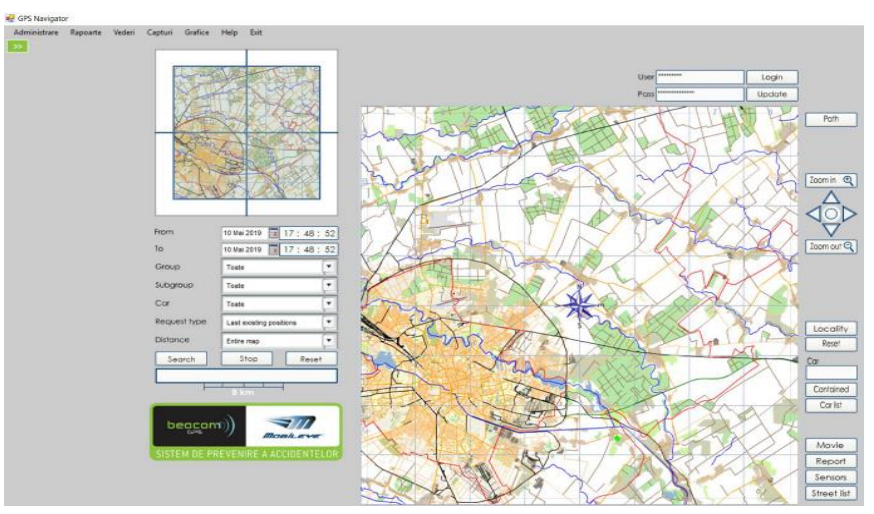

Fig. 12 Level 2 accuracy of own tracking maps

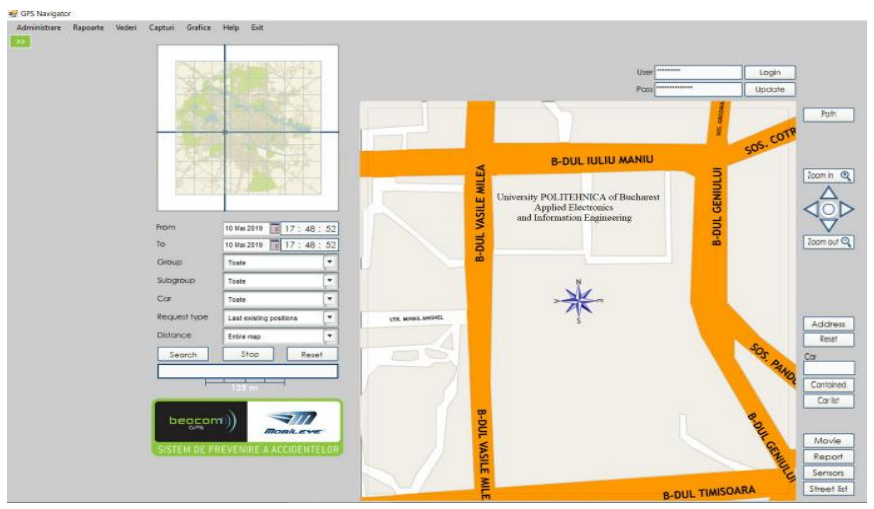

Fig. 14 Detail of level 3 accuracy of same map

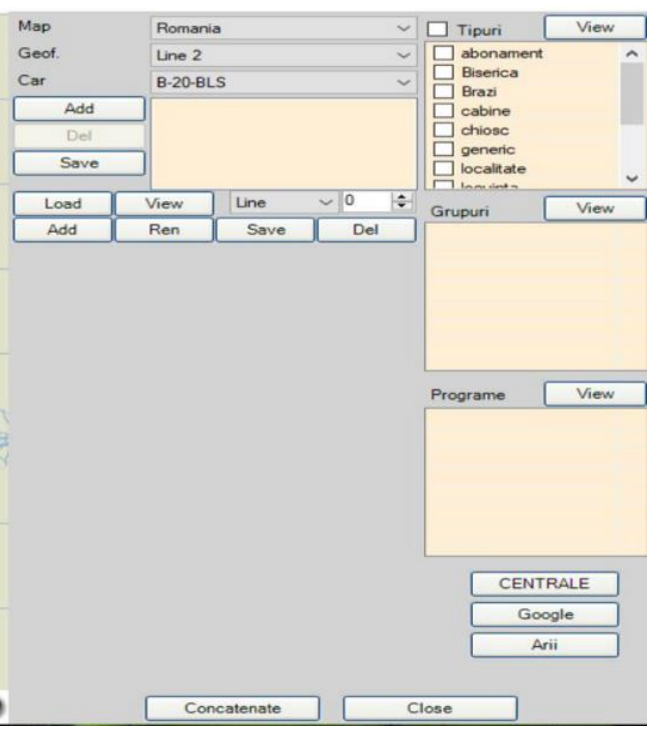

g. 15 Geofencing results

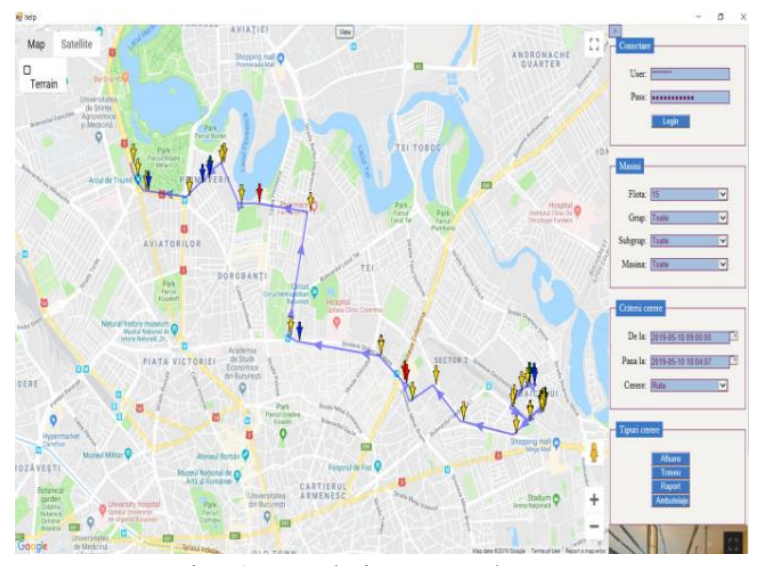

Fig. 17 Real-time travel routes 
Regarding real time mobile units viewing and tracking, we have implemented our own program that allows us to restrict the area of traffic by drawing the displaced area of movement (general called Geofencing), being physically visible on the map. Fig. 15 illustrates such a restriction points that is actually the fence limiting movement; If the border is passed, the system sends SMS alert to administrator, so permanent surveillance on PC monitor is not necessary. The particularity towards other similar achievements is the use of our own maps rather than Google's. The second is the possibility to choose how to delimit the allowed area: In Fig. 15 we showed only the punctuation of boundaries, which are linked to each other, and also through physical marking an area of travel which can be adjusted by simply dragging whit mouse.

Our programs are also written to generate a series of reports (of which two have already been mentioned in Figs. 7 and 8 ). Another thought-based and implemented feature is the tracking of real-time positioning of the device being tracked; by the colors allocated for various situations, the administrator, after a certain time of use, can realize the deviations from the imposed rules. Fig. 16 illustrates such a report, and in Fig. 17 we have illustrated another type of query that shows the movement of a fleet on a certain day and pre-set hourly.

\section{Conclusions}

This paper presents detailed aspects related to progress of our own WN tracking device, with GSM / GPS / GPRS features. Thus the concern of improvement and optimization of energy consumption had aimed on both hardware and software component. Developed hardware modules are those of Section 3, Figs. 3-5, specifying that they work in real time, and the side of software applications is done in Section 4.

We show that hardware solution from Fig. 5 represents the new concept that improves the life of its own power supply and provides the ability to bind to a hardware and software management dispatch system, for data and alarm transmission and reception, thus becoming a coordinating node in a network topology.

As far as software design is concerned, we have looked for the management and handling programs to be as easy and simple to use as possible, that's why the programs needed for the mobile units were written in combined language $\mathrm{C} / \mathrm{C}++$ / Java, and for servers only Java programming language.

We adopted the differential transmission strategy for significant data packets, the difference measurements are calculated in mobile units and only data that is perceived by the software as alerts are transmitted; the user is responsible for choosing the communication interface and defining all related metrics.

We introduced two other intermediate software stages in the data transmission, described by the pseudocode on subsection 5.2 thus managing to improve the balance of energy consumption; system maintenance is done by dedicated programs that perform tasks and database management.

Section 6 describes the results obtained for both hardware and software solutions. In subsection 6.1 we made a brief description of the experiment, results and methods used in the hardware area, while subsection 6.2 is allocated to software results, in fact much more spectacular in our opinion. The programs for which we presented the results of subsection 6.2 are proprietary code, runs on any computer with an Internet connection and Windows system and not limit real-time access to monitored vehicles or fixed targets. Particularities with respect to other similar achievements in the field: 1 . The use of own maps adapted after Google; 2. The possibility to choose the delimitation mode for the allowed area.

However, we consider the following achievements for further development:

(1) An architecture for a new device that includes a WiFi module, Bluetooth and internal battery;

(2) Wireless charging of electric cars; 
(3) Capturing energy from surrounding electromagnetic sources that deliberately transfers energy from: Radio frequency, Solar and wind energy, Thermal energy;

(4) Application in the existing intelligent buildings without additional wiring, a wireless monitoring system based on passive infrared sensors (PIR);

(5) Using thermal energy dissipated by wireless devices for generating electricity.

(6) We can develop our application for any other type of real-time tracking.

The paper present our efforts to improve the use of WS in WN applications. These have been materialized in a number of practical applications for locating various fixed and mobile targets like:

(1) Mobile targets with the hardware modules described in Section 3 and shown in Figs. 3-5;

(2) Monitoring applications of the fixed oil wells with the camera and Passive Infrared Sensor (PIR);

(3) Monitoring of maritime containers. Therefore, we can say that the purpose, for which we have designed all hardware and software solutions presented in this paper, has been reached.

\section{Conflicts of Interest}

The authors declare no conflict of interest

\section{References}

[1] J. Wang, J. Cho, S. Lee, K. C. Chen, and Y. K. Lee, "Hop-Based Energy Aware Routing Algorithm for Wireless Sensor Networks," IEICE Transactions on Communication 2010, vol. E93.B, no. 2, pp. 305-316, 2010.

[2] W. Heinzelman, “Application-Specific Protocol Architectures for Wireless Networks," Ph.D. Thesis, Massachusetts Institute of Technology: Cambridge, MA, USA, pp. 84-86, 2000.

[3] J. Wang, J. U. Kim, S. Lei, Y. Niu, and L. Sungyoung, “A Distance-Based Energy Aware Routing Algorithm for Wireless Sensor Networks," Sensors, vol. 10, pp. 9493-9511, 2010.

[4] O. Younis and S. Fahmy, "HEED: A Hybrid, Energy-Efficient, Distributed Clustering Approach for Ad Hoc Sensor Networks," IEEE Transactions on Mobile Computing, vol. 3, no. 4, pp. 366-379, October-December 2004, doi:10.1109/TMC.2004.41.

[5] C. H. Yassin and M. C. Rosu, "Energy-Saving Strategies in Monitoring for Wireless Sensor Networks," The 21th IEEE International Symposium for Design and Technology in Electronic Packaging (SIITME 2015), Brasov, Romania October 2015.

[6] S. Murugananham and P. R. Mukesh, "Real Time Web-Based Vehicle Tracking Using GPS," World Academy of Science, Engineering and Technology, vol. 61, pp. 91-99, 2010.

[7] N. Chadil, A. Russameesawang, and P. Keeratiwintakorn, "Real-Time Tracking Management System Using GPS, GPRS and Google Earth," International Conference on Electrical Engineering/Electronics, Computer, Telecommunications and Information Technology, Krabi, 2008, pp. 393-396.

[8] S. M. Kale and A. Kumar, "Location Tracking and Data Compression for Accurate Energy Efficient Localization Using Gsm System," International Journal of Innovative Research in Science, Engineering and Technology, vol. 3, no. 3, pp. 10163-10167, March 2014.

[9] M. A. Labrador and P. M. Wightman, "Topology Control in Wireless Sensor Networks; with a Companion Simulation Tool for Teaching and Research,” Springer Science and Business Media B. V., 2009.

[10] F. Ingelrest, D. Simplot-Ryl, and I. Stojmenovic, "Optimal Transmission Radius for Energy Efficient Broadcasting Protocols in Ad Hoc Networks," IEEE Transactions on Parallel and Distributed Systems, vol. 17, no. 6, pp. 536-547, June 2006.

[11] R. Zhang and M. A. Labrador, "Energy-Aware Topology Control in Heterogeneous Wireless Multihop Networks," Proceedings 2nd International Symposium on Wireless Pervasive Computing, Puerto Rico, 2007.

[12] G. Anastasi, M. Conti, M. Di Francesco, and A. Passarella, "Energy Conservation in Wireless Sensor Networks: A Survey," Ad Hoc Networks, vol. 7, no. 3, pp. 537-568, 2009.

[13] R. Willett, A. Martin, and R. Nowak, "Backcasting: Adaptive Sampling for Sensor Networks," Third International Symposium on Information Processing in Sensor Networks, IPSN, Berkeley, CA, USA, 2004, pp. 124-133. 
[14] A. D. Marbini and L. E. Sacks, “Adaptive Sampling Mechanisms in Sensor Networks,” Proceedings LCS, 2003.

[15] A. Jain and E. Y. Chang, "Adaptive Sampling for Sensor Networks," DMSN '04 Proceedings of the 1st International Workshop on Data Management for Sensor Networks: In Conjunction with VLDB 2004, pp. 10-16, 2004.

[16] S. Goel and T. Imielinski, "Prediction-Based Monitoring in Sensor Networks: Taking Lessons from MPEG," ACM SIGCOMM Computer Communication Review, vol. 31, no. 5, pp. 82-98, 2001.

[17] B. Gedik, L. Liu, and P. S. Yu, “ASAP: An Adaptive Sampling Approach to Data Collection in Sensor Networks,” IEEE Transactions on Parallel and Distributed Systems, vol. 18, no. 12, pp. 1766-1783.

[18] S. Goel, A. Passarella, and T. Imielinski, "Using Buddies to Live Longer in a Boring World," Fourth Annual IEEE International Conference on Pervasive Computing and Communications Workshops, (PERCOMW'06), Pisa, 2006.

[19] N. Kimura and S. Latifi, "A Survey on Data Compression in Wireless Sensor Networks," International Conference on Information Technology, Coding and Computing (ITCC'05), 2005, vol. 2, pp. 8-13.

[20] W. Heinzelman, A. Chandrakasan, and H. Balakrishnan, "Energy-Efficient Communication Protocol for Wireless Microsensor Networks," Proceedings of the 33rd Annual Hawaii International Conference System Sciences, Maui, HI, USA, January 2000, vol. 2, pp. 1-10.

[21] W. B. Heinzelman, A. P. Chandrakasan, and H. Balakrishnan, "An Application-Specific Protocol Architecture for Wireless Microsensor Networks," IEEE Transactions on Wireless Communications, vol. 1, no. 4, pp. 660-670, October 2002.

[22] K. Akkaya and M. Younis, “A Survey on Routing Protocols for Wireless Sensor Networks,” Ad Hoc Networks, vol. 3, no. 3, pp. 325-349, May 2005.

[23] W. Zhang and G. Cao, "DCTC: Dynamic Convoy Tree-Based Collaboration for Target Tracking in Sensor Networks," IEEE Transactions on Wireless Communications, vol. 3, no. 5, pp. 1689-1701, September 2004.

[24] W. Zhang and G. Cao, “Optimizing Tree Reconfiguration for Mobile Target Tracking in Sensor Networks," IEEE INFOCOM, Hong Kong, 2004, vol. 4, pp. 2434-2445.

[25] A. Goel and E. Deborah, "Simultaneous Optimization for Concave Costs: Single Sink Aggregation or Single Source Buy-at-Bulk," Algorithmica, vol. 43, pp. 5-15, 2003.

[26] R. Cristescu, B. Beferull-Lozano, and M. Vetterli, “On Network Correlated Data Gathering,” IEEE INFOCOM 200, Hong Kong, 2004, vol. 4, pp. 2571-2582.

[27] Y. Zhu, K. Sundaresan, and R. Sivakumar, "Practical Limits on Achievable Energy Improvements and Useable Delay Tolerance in Correlation Aware Data Gathering in Wireless Sensor Networks," Second Conference IEEE SECON, Santa Clara, CA, USA, 2005, pp. 328-339,.

[28] K. W. Fan, S. Liu, and P. Sinha, “On the Potential of Structure-Free Data Aggregation in Sensor Networks,” Proceedings 25th Conference INFOCOM, Barcelona, April 2006, pp. 1-12.

[29] K. W. Fan, S. Liu, and P. Sinha, "Scalable Data Aggregation for Dynamic Events in Sensor Networks," Proceedings of the 4th International conference on Embedded networked sensor systems (SenSys'06), Boulder, CO, USA, 2006, pp. 181-194.

[30] S. Mahfoudh and P. Minet, "An Energy Efficient Routing Based on OLSR in Wireless ad Hoc and Sensor Networks," 22nd International Conference on Advanced Information Networking and Applications -Workshops, Okinawa, 2008, pp. 1253-1259.

[31] http://tools.ietf.org/html/rfc6206

[32] G. Pei, M. Gerla, and T. W. Chen, "Fisheye State Routing: A Routing Scheme for Ad Hoc Wireless Networks," IEEE International Conference on Communications ICC Global Convergence through Communications, New Orleans, LA, USA, 2000, vol. 1, pp. 70-74.

[33] M. van Der Schaar, “Cross-Layer Wireless Multimedia Transmission: Challenges, Principles, and New Paradigms,” IEEE Wireless Communications, vol. 12, no. 4, pp. 50-58, 2005.

[34] M. Garey and D. Johnson, Computers and Intractability: A Guide to the Theory of NP Completeness. W. H. Freeman \& Co. New York, NY, USA, 1990.

[35] J. Wu and H. Li, "On Calculating Connected Dominating Set for Efficient Routing in Ad Hoc Wireless Networks," Proceedings the 3rd International Workshop on Discrete Algorithms and Methods for Mobile Computing and Communications DIALM, 1999, pp. 7-14.

[36] F. Dai and J. Wu, "An Extended Localized Algorithm for Connected Dominating Set Formation in Ad Hoc Wireless Networks," IEEE Transactions on Parallel and Distributed Systems, vol. 15, no. 10, pp. 908-920, 2004.

[37] F. Ingelrest, D. Simplot-Ryl, and I. Stojmenovic, "Smaller Connected Dominating Sets in Ad Hoc and Sensor Networks Based on Coverage by Two-Hop Neighbors," 2nd International Conference on Communication System Software and Middleware, Bangalore, India, 2007, pp. 1-8.

[38] K. Alzoubi, P. J. Wan, and O. Fieder, "Distributed Heuristics for Connected Dominating Sets in Wireless Ad Hoc Networks," Journal of Communications and Networks, vol. 4, no. 1, pp. 22-29, 2002.

[39] B. Han, H. H. Fu, L. Li, and W. Jia, "Efficient Construction of Connected Dominating Set in Wireless Ad Hoc Networks," IEEE International Conference MASS 2004, (IEEE Cat. No.04EX975), pp. 570-572, Fort Lauderdale, FL, USA, 2004.

[40] E. O. Blass, J. Horneber, and M. Zitterbart, “Analyzing Data Prediction in Wireless Sensor Networks," IEEE Vehicular Technology Conference, 2008, pp. 86-87. 
[41] K. Zeng, W. Lou, J. Yang, and D. R. I. Brown, "On Geographic Collaborative Forwarding in Wireless Ad Hoc and Sensor Networks," International Conference on Wireless Algorithms, Systems and Applications (WASA2007), 2007, pp. 11-18.

[42] L. Jun and J. P. Hubaux, “Joint Mobility and Routing for Lifetime Elongation in Wireless Sensor Networks," Proceedings of 24th Annual Joint Conference of the IEEE Computer and Communications Societies, vol. 3, pp. 1735-1746, Miami, FL, 2005.

[43] M. Bhardwaj and A. P. Chandrakasan, "Bounding the Lifetime of Sensor Networks via Optimal Role Assignments," Proceedings of 21st Annual Joint Conference of IEEE Computer and Communications Societies, New York, USA, 2002, vol. 3, pp. 1587-1596.

[44] M. Cagalj, J. P. Hubaux, and C. Enz, "Minimum-Energy Broadcast in All-Wireless Networks: Np-Completeness and Distribution issues," Proceedings of 8th Annual International Conference on Mobile Computing and Networking, Atlanta, USA, 2002, pp. 172-182.

[45] I. Papadimitriou and L. Georgiadis, "Energy-Aware routing to Maximize Lifetime in Wireless Sensor Networks with Mobile Sink," Journal of Communications Software and Systems, vol. 2, no. 2, pp. 141-151, June 2006.

[46] L. Pelusi, A. Passarella, and M. Conti, "Opportunistic Networking: Data Forwarding in Disconnected Mobile Ad Hoc Networks," IEEE Communications Magazine, vol. 44, no. 11, pp. 134-141, November 2006.

[47] R. C. Shah, S. Roy, S. Jain, and W. Brunette, "Data MULEs: Modeling a Three-Tier Architecture for Sparse Sensor Networks," Proceedings IEEE International Workshop on Sensor Network Protocols and Applications, USA, 2003, pp. $30-41$.

[48] C. H. Ou and K. F. Ssu, "Routing with Mobile Relays in Opportunistic Sensor Networks," 18th IEEE Annual International Symposium on Personal, Indoor and Mobile Radio Communications, Athens, 2007, pp. 1-5.

[49] S. Meguerdichian and M. Potkonjak, "Low Power 0/1 Coverage and Scheduling Techniques in Sensor Networks," UCLA Technical Reports 030001, January 2003.

[50] K. Chakrabarty, et al., "Grid Coverage for Surveillance and Target Location in Distributed Sensor Networks," IEEE Transactions on Computers, vol. 51, no. 12, pp. 1448-1453, December 2002.

[51] B. Chen, K. Jamieson, H. Balakrishnan, and R. Morris, "Span: An Energy Efficient Co-Ordination Algorithm for Topology Maintenance in Ad Hoc Wireless Networks," ACM Wireless Networks, vol. 8, no. 5, pp. 481-494, September 2002.

[52] X. Wang, G. Xing, Y. Zhang, C. Lu, R. Pless, and C. Gill, "Integrated Coverage and Connectivity Configuration in Wireless Sensor Networks," Proceedings of SenSys, pp. 28-39, LA, USA, 2003.

[53] M. Cardei and D. Du, "Improving Wirelessn Sensor Network Lifetime Through Power Aware Organization," ACM Journal of Wirless Networks, vol. 11, no. 3, May 2005.

[54] M. Cardei, M. Thai, Y. Li, and W. Wu, "Energy-Efficient Target Coverage in Wireless Sensor Networks," Proceedings of 24th Annual Joint Conference of the IEEE INFOCOM, Miami, FL, USA, 2005, pp. 1976-1984.

[55] V. Rajendran, K. Obraczka, and J. J. Garicia-Luna-Aceves, "Energy-Efficient, Collision-Free Medium Access Control for Wireless Sensor Networks,” Proceedings ACM SenSys, LA, CA, November 2003, pp. 181-192.

[56] V. Rajendran, "Energy-Efficient, Application Aware Medium Access for Sensor Networks," Proceedings 2nd IEEE Conference on Mobile Ad-Hoc and Sensor Systems (MASS), 2005, pp. 8-630.

[57] W. L. Lee, A. Datta, and R. Cardell-Oliver, "FlexiTP: A Flexible-Schedule-Based TDMA Protocol for Fault-Tolerant and Energy-Efficient Wireless Sensor Networks," IEEE Transactions on Parallel and Distributed Systems, vol. 19, no. 6, pp. 851-864, June 2008.

[58] S. Gobriel, D. Mousse, and R. Cleric, "TDMA-ASAP: Sensor Network TDMA Scheduling with Adaptive Slot Stealing and Parallelism," 29th IEEE International Conference on Distributed Computing Systems, Montreal, QC, 2009, pp. 458-465.

[59] W. Ye, J. Heidemann, and D. Estrin, "Medium Access Control with Coordinated Adaptive Sleeping for Wireless Sensor Networks," IEEE/ACM Transactions on Networking, vol. 12, no. 3, pp. 493-506, June 2004.

[60] T. Van Dam and K. Langendoen, "An Adaptive Energy Efficient MAC Protocol for Wireless Sensor Networks," Proceedings of 1st International Conference on Embedded Networked Sensor Systems, November 2003, pp. 171-180.

[61] G. Lu, B. Krishnamachari, and C. S. Raghavendra, "An Adaptive Energy Efficient and Low-Latency Mac for Data Gathering in Wireless Sensor Networks," Proceedings 18th International Parallel and Distributed Processing Symposium, New Mexico, USA, April 2004, vol. 224, pp. 26-30.

[62] J. Polastre, J. Hill, and D. Culler, "Versatile Low Power Media Access for Sensor Networks," Proceedings 2nd ACM Conference on Embedded Networked Sensor Systems (SenSys), Maryland, November 2004.

[63] I. Rhee, A. Warrier, M. Aia, and J. Min, “Z-MAC: A Hybrid MAC for Wireless Sensor Networks,” IEEE/ACM Transactions on Networking, vol. 16, no. 3, pp. 511-524, June 2008.

[64] S. Mahfoudh, G. Chalhoub, P. Minet, M. Misson, and I. Amdouni, "Node Coloring and Color Conflict Detection in Wireless Sensor Networks," Future Internet, vol. 2, no. 4, pp. 469-504, 2010.

[65] A. Salman, "Real Time Vehicle Tracking System and Energy Reduction," University of Waterloo Library, Ontario, Canada, 2017. 
[66] I. F. Akyildiz, W. Su, Y. Sankarasubramaniam, and E. Cayirci, "Wireless Sensor Networks: A Survey,” Computer Network, vol. 38, pp. 393-422, March 2002.

[67] C. M. Sadler and M. Martonosi, "Data Compression Algorithms for Energy-Constrained Devices in Delay Tolerant Networks," Proceedings of the 4th International Conference on Embedded Networked Sensor Systems, SenSys, Boulder, USA, 2006, pp. 265-278.

[68] I. Buchmann, "Batteries in a Portable World: A Handbook on Rechargeable Batteries for Non-Engineers," 3rd ed. Richmond: Cadex Electronics, 2011.

[69] https://www.microchip.com/wwwproducts/en/PIC32MX775F256H.

[70] M. C. Rosu, A. Iliesiu, Y. C. Hamed, and S. G. Obreja, "A GI Proposal to Display ECG Digital Signals Wirelessly Real-Time Transmitted Onto a Remote PC," Advances in Technology Innovation, vol. 3, no. 3, pp. 118-125, March 2018.

[71] https://msoon.github.io/powermonitor/PowerTool/doc/Power\%20Monitor\%20Manual.pdf

[72] https://en.freedownloadmanager.org/Windows-PC/Monsoon-PowerTool-FREE.html

\section{Appendix 1 - Abbreviations from Table 6}

\begin{tabular}{|c|c|}
\hline APTEEN & Adaptive Periodic TEEN \\
\hline ASAP & Accelerated SAP \\
\hline BMAC & Berkeley MAC \\
\hline CADR & Constrained Anisotropic Diffusion Routing \\
\hline COUGAR & Data-Centric CADR Protocol \\
\hline CSMA & Carrier Sense Multiple Access \\
\hline DCTC & Direct Connect Text Client protocol \\
\hline DiD & Directed Diffusion technique \\
\hline DLMST & Directed LMST \\
\hline DMAC & Directional MAC \\
\hline DRNG & Directed RNG \\
\hline FLAMA & Flow-Aware Medium Access \\
\hline FlexiTP & Flexible based TDMA Protocol \\
\hline GAF & Geographic Adaptive Fidelity \\
\hline GEAR & Geographical and Energy Aware Routing \\
\hline LEACH & Low-Energy Adaptive Clustering Hierarchy protocol \\
\hline LMST & Local Minimum Spanning Tree \\
\hline MAC & Medium Access Control \\
\hline MST & Multiple Shared Tree \\
\hline PEGASIS & Power-Efficient Gathering in Sensor Information Systems \\
\hline READ & Residual Energy Aware Dynamic \\
\hline RNG & Random Number Generator \\
\hline SERENA & SchEduling RoutEr Nodes Activity \\
\hline SMAC & Sensor Media Access Control \\
\hline SMT & Steiner Minimum Tree \\
\hline SPAN & Switch Port Analyzer \\
\hline SPEED & Routing Protocol with QoS \\
\hline SPIN & Sensor Protocols for Information via Negotiation \\
\hline SYNC & Data synchronization \\
\hline TDMA & Time Division Multiple Access \\
\hline TDMA/CA & Time Division Multiple Access/ Control Access \\
\hline TEEN & Threshold-Sensitive Energy Efficient Sensor Network Protocol \\
\hline ToD & Tree on Directed acyclic graph \\
\hline TRAMA & Traffic-Adaptive Medium Access Protocol \\
\hline ZMAC & Zebra MAC \\
\hline
\end{tabular}

\section{Appendix 2 - Datasheets Links}

1. Huawei GTM900 GSM/GPRS Wireless Module; available:

https://www.digchip.com/datasheets/download_datasheet.php?id=4375635\&part-number=GSM900

2. Ublox NEO-6M GPS Modul; available: https://www.waveshare.com/w/upload/2/2c/NEO-6-DataSheet.pdf.

3. NXP Semiconductors - LPC2361/62 $\mu$ C; available: https://www.nxp.com/docs/en/data-sheet/LPC2361_62.pdf. 
4. Ublox LEON-G1 series GSM/GPRS module; available: https://www.u-blox.com/sites/default/files/products/documents/ LEON-G1_DataSheet_\%28UBX-13004887\%29.pdf.

5. U-blox MAX-6Q-0-000 GPS Modul; available: https://www.iot-lab.info/wp-content/uploads/2013/10/GPS_MAX6.pdf.

6. SIM900 GSM/GPRS Modul; available: https://datasheet.octopart.com/SIM900-Simcom-datasheet-17594122.pdf.

7. STM32F103RB Microcontroller $(\mu \mathrm{C})$; available: https://www.st.com/content/st_com/en/products/microcontrollers-microprocessors/stm32-32-bit-arm-cortex-mcus/stm32-mainstream-mcus/stm32fl- series/stm32f103/stm32flo3rb.html.

8. Microchip-PIC32 $\mu$ C; available: https://ro.mouser.com/datasheet/2/268/60001156J-1315355.pdf. 